\title{
Legume species differ in the responses of their functional traits to plant diversity
}

\author{
Roscher, C ; Schmid, B ; Buchmann, N ; Weigelt, A ; Schulze, E D
}

\begin{abstract}
Plants can respond to environmental impacts by variation in functional traits, thereby increasing their performance relative to neighbors. We hypothesized that trait adjustment should also occur in response to influences of the biotic environment, in particular different plant diversity of the community. We used 12 legume species as a model and assessed their variation in morphological, physiological, life-history and performance traits in experimental grasslands of different plant species $(1,2$, $4,8,16$ and 60) and functional group (1-4) numbers. Mean trait values and their variation in response to plant diversity varied among legume species and from trait to trait. The tall-growing Onobrychis viciifolia showed little trait variation in response to increasing plant diversity, whereas the species with shorter statures responded in apparently adaptive ways. The formation of longer shoots with elongated internodes, increased biomass allocation to supporting tissue at the cost of leaf mass, reduced branching, higher specific leaf areas and lower foliar d13C values indicated increasing efforts for light acquisition in more diverse communities. Although leaf nitrogen concentrations and shoot biomass:nitrogen ratios were not affected by increasing plant diversity, foliar d15N values of most legumes decreased and the application of the $15 \mathrm{~N}$ natural abundance method suggested that they became more reliant on symbiotic N2 fixation. Some species formed fewer inflorescences and delayed flowering with increasing community diversity. The observed variation in functional traits generally indicated strategies of legumes to optimize light and nutrient capturing, but they were largely speciesdependent and only partly attributable to increasing canopy height and community biomass with increasing plant diversity. Thus, the analysis of individual plant species and their adjustment to growth conditions in communities of increasing plant diversity is essential to get a deeper insight into the mechanisms behind biodiversity-ecosystem functioning relationships.
\end{abstract}

DOI: https://doi.org/10.1007/s00442-010-1735-9

Posted at the Zurich Open Repository and Archive, University of Zurich

ZORA URL: https://doi.org/10.5167/uzh-42712

Journal Article

Accepted Version

Originally published at:

Roscher, C; Schmid, B; Buchmann, N; Weigelt, A; Schulze, E D (2011). Legume species differ in the responses of their functional traits to plant diversity. Oecologia, 165(2):437-452.

DOI: https://doi.org/10.1007/s00442-010-1735-9 
1 Legume species differ in the responses of their functional traits to plant 2 diversity

3

4 Christiane Roscher ${ }^{1}$, Bernhard Schmid ${ }^{2}$, Nina Buchmann ${ }^{3}$, Alexandra Weigelt ${ }^{4,5}$, Ernst-Detlef $5 \quad$ Schulze $^{1}$

6

$7 \quad{ }^{1}$ Max Planck Institute for Biogeochemistry, POB 100164, D-07701 Jena, Germany

$8{ }^{2}$ Institute of Evolutionary Biology and Environmental Studies, University of Zurich,

9 Winterthurerstrasse 190, CH-8057 Zurich, Switzerland

$10{ }^{3}$ Institute of Plant, Animal and Agrosystems Sciences, ETH Zurich, Universitätsstrasse 2, $11 \quad$ CH-8092 Zurich, Switzerland

$12{ }^{4}$ Institute of Ecology, Friedrich Schiller University Jena, Dornburger Strasse 159, D-07743

13 Jena, Germany

145 present address: University of Leipzig, Institute of Biology I, Johannisallee 21-23, D-04103

15 Leipzig, Germany

16

17 Correspondence: Christiane Roscher, Max Planck Institute for Biogeochemistry, POB 100164, D-07701 Jena Phone: ++49 3641 576227; Fax: ++49 3641 577100; Email: croscher@bgc-jena.mpg.de

MS details: 292 words in abstract, 8233 words in full text, 4 figures, 3 tables, Supplementary 


\section{Abstract}

Plants can respond to environmental impacts by variation in functional traits, thereby increasing their performance relative to neighbors. We hypothesized that trait adjustment should also occur in response to influences of the biotic environment, in particular different plant diversity of the community. We used 12 legume species as a model and assessed their variation in morphological, physiological, life-history and performance traits in experimental grasslands of different plant species $(1,2,4,8,16$ and 60$)$ and functional group (1 to 4) numbers. Mean trait values and their variation in response to plant diversity varied among legume species and from trait to trait. The tall-growing Onobrychis viciifolia showed little trait variation in response to increasing plant diversity, whereas the species with shorter statures responded in apparently adaptive ways. The formation of longer shoots with elongated internodes, increased biomass allocation to supporting tissue at the cost of leaf mass, reduced branching, higher specific leaf areas and lower foliar $\delta^{13} \mathrm{C}$ values indicated increasing efforts for light acquisition in more diverse communities. Although leaf nitrogen concentrations and shoot biomass:nitrogen ratios were not affected by increasing plant diversity, foliar $\delta^{15} \mathrm{~N}$ values of most legumes decreased and the application of the ${ }^{15} \mathrm{~N}$ natural abundance method suggested that they became more reliant on symbiotic $\mathrm{N}_{2}$ fixation. Some species formed fewer inflorescences and delayed flowering with increasing community diversity. The observed variation in functional traits generally indicated strategies of legumes to optimize light and nutrient capturing, but they were largely species-dependent and only partly attributable to increasing canopy height and community biomass with increasing plant diversity. Thus, the analysis of individual plant species and their adjustment to growth conditions in communities of increasing plant diversity is essential to get a deeper insight into the mechanisms behind biodiversity-ecosystem functioning relationships. 
51 Key words: biodiversity, functional traits, legumes, species identity, trait variation 
52

53

54

\section{Introduction}

Growing awareness of widespread reductions in species diversity during the last decades has stimulated intensive research on the consequences of these changes on ecosystem functioning. A number of experimental studies in grassland ecosystems suggest strong and consistent positive effects of biodiversity on several ecosystem processes, e.g. primary productivity or nutrient cycling (see reviews in Hooper et al. 2005, Balvanera et al. 2006). In spite of evidence that complementarity among species contributes to positive biodiversity-ecosystem functioning relationships (Cardinale et al. 2007), the biological mechanisms subsumed under the term "complementarity" are not well understood. Diversity in functional characteristics is generally regarded to increase complementary use of essential resources such as light, water, carbon dioxide, minerals, and space among plant species in a community (Walker et al. 1999, Díaz and Cabido 2001). Resource-use efficiency measured at the community level on average increases with species richness and results in increased community biomass, canopy density and height (Spehn et al. 2000, Lorentzen et al. 2008) and soil nutrient exploitation (Palmborg et al. 2005, Oelmann et al. 2007). However, not all species contribute equally to the overall positive effects of biodiversity on primary productivity, rather some species may overyield whereas others may underyield in plant communities of increasing diversity (e.g. Hector et al. 2002, van Ruijven and Berendse 2003, Roscher et al. 2007).

Species performance is the net result of a number of morphological, physiological and phenological traits (= functional traits) operating from the cell to whole-plant level (Violle et al. 2007). Environment-induced trait variation (= phenotypic plasticity) is well known as the strategy by which plants maximize their performance under different abiotic and biotic conditions (e.g. Bradshaw 1965, Schlichting 1986, Schmid 1990). Nevertheless, adjustment of a trait is not necessarily adaptive, because it may be due to genetic correlation with other traits or may be a consequence of passive reductions in growth due to resource limitations (van 
Kleunen and Fischer 2005). According to the "optimal allocation theory" (Bloom et al. 1985, McConnaughay and Coleman 1999), plants tend to adjust their allocation and invest a higher proportion to organs that optimize the acquisition of the most limiting resource. In addition, perennial species often reduce their allocation into reproductive structures in response to resource limitation (Chiariello and Gulmon 1991).

So far the relationship between plant community diversity and variation in plant functional traits has attracted little attention in the increasing effort to understand the positive effects of plant species diversity on ecosystem processes (Callaway 2007). In the present study carried out in a large biodiversity experiment located on a nutrient-rich floodplain site (Jena Experiment, Roscher et al. 2004) we focus on legumes, which are often considered as a relatively homogeneous plant functional group in grasslands. They are unique in their ability to fix symbiotically atmospheric nitrogen. Several biodiversity experiments have shown that legumes are keystone species in generating the observed biodiversity effects on ecosystem processes (Hooper et al. 2005). Nevertheless, effects associated with legume presence are highly variable, probably due to the identity of particular legume species and different environmental conditions (Spehn et al. 2002). In temperate grasslands, light and nutrients are among the most limiting factors that affect plant growth. Increasing canopy height and productivity at the community level with increasing species richness alter the amount and quality of available resources for individual species within these communities. Although legumes do not directly depend on the available soil nitrogen, the rates of energy-demanding $\mathrm{N}_{2}$ fixation may be reduced under high soil nitrogen supply (Marschner 1995). Thus, we recorded data on shoot morphology, biomass allocation to different aboveground plant organs and measured leaf and shoot nitrogen concentrations as traits which were supposed to reflect strategies of light and nitrogen acquisition and retention by individual plants and may indicate changes in the growth environment. We used foliar $\mathrm{C}$ isotope ratios $\left(\delta^{13} \mathrm{C}\right)$ as integrated long- 
102 term measure of photosynthetic activity and stomatal conductance, which depend on light

103 availability, air humidity and plant nutritional status (Farquhar et al. 1989). We determined

104 foliar $\mathrm{N}$ isotope ratios $\left(\delta^{15} \mathrm{~N}\right)$ and applied the ${ }^{15} \mathrm{~N}$ natural abundance method (Amarger et al.

105 1979) to assess plant diversity effects on $\mathrm{N}_{2}$ fixation in legumes. In addition, we studied

106 legume plant characteristics that may serve as indicators for plant individual performance

107 such as shoot biomass or number of inflorescences. We related these plant characteristics to

108 plant diversity — in terms of species and functional group richness — and community

109 characteristics - in terms of canopy height and community biomass. We tested the following

110 hypotheses: (1) Increasing plant diversity affects variation in trait values associated with

111 strategies in light and nitrogen acquisition and retention. (2) Plant diversity effects are partly

112 but not fully mediated by concomitant increases in community biomass and canopy height.

113 (3) Plant diversity effects on trait variation vary among legume species, suggesting different

114 strategies of species to respond to their biotic environment in ways which may increase

115 complementary resource use.

117 Material and methods

\section{Experimental set-up}

120 The study was carried out as part of the Jena Experiment, a large integrated biodiversity

121 experiment started in 2002 (Roscher et al. 2004). The experimental site lies in the floodplain

122 of the river Saale near to the city of Jena (Thuringia, Germany, $50^{\circ} 55^{\prime} \mathrm{N}, 11^{\circ} 35^{\prime} \mathrm{E}, 130 \mathrm{~m}$

123 a.s.1.) and was used as an agricultural field for 40 years prior to the establishment of the

124 biodiversity experiment. The area around Jena has a mean annual air temperature of $9.3^{\circ} \mathrm{C}$

125 and a mean annual precipitation of $587 \mathrm{~mm}$ (Kluge and Müller-Westermeier 2000). The soil

126 of the experimental site is a Eutric Fluvisol developed from up to $2 \mathrm{~m}$ thick loamy fluvial 
127 sediments. Due to flooding dynamics, soil texture ranges from sandy loam near the river to

128 silty clay with increasing distance from the river.

129 Sixty grassland species typically occurring in Central European semi-natural, species-rich

130 grasslands (Arrhenatherion alliance according to the vegetation classification of Ellenberg,

131 1988) were selected as species pool for the experiment. Species were divided into four

132 functional groups following the results of a cluster analysis with a literature-based trait

133 matrix: grasses (16 species), legumes (12 species), small herbs (12 species) and tall herbs (20

134 species). The design of the Jena Experiment ensures that the presence/absence of each

135 functional group (FG) is minimally confounded with species number (SR, see Roscher et al.

136 2004). In total, the main experiment comprises 82 plots of $20 \times 20 \mathrm{~m}$ size: 16 monocultures $(1$

137 FG), 16 two-species mixtures (1 or 2 FG), 16 four-species mixtures (1 to 4 FG), 16 eight-

138 species mixtures (1 to 4 FG), 14 sixteen-species mixtures (1 to 4 FG) and four replicates with

139 a mixture of the complete species pool. The number of replicates with sixteen species was

140 lower because pure legume or small herb mixtures were not possible at this species-richness

141 level. Particular species compositions were compiled by independent random draws with

142 replacement. In addition, all species were established in replicated monocultures of $3.5 \times 3.5$

$143 \mathrm{~m}$. Sown density aimed to establish 1000 seedlings per $\mathrm{m}^{2}$ in a substitutive design, in which

144 constant total density was achieved by reducing sowing densities of individual species

145 according to the number of species in the mixture (Jolliffe 2000). Number of sown seeds was

146 adjusted for germination rates from preliminary laboratory tests. Plots were grouped into four

147 blocks parallel to the river, each of them containing the same number of experimental

148 communities per species-richness level. All plots were mown twice a year in early June and

149 September corresponding to the typical management regime for extensive meadows in the

150 region and were not fertilized during the experimental period. Plots were weeded twice per

151 growing season when the vegetation was low and the canopy not completely closed (early 
152 April at the beginning of the growing season and early July after mowing). For further details

153 see Roscher et al. (2004).

\section{Data collection}

156 In this study we analysed all legume species belonging to the experimental species pool

157 (Table 1). Plant modules (individual shoots) served as basic unit for all measurements because

158 the ability of some legume species to grow with above- or belowground runners hampers a

159 distinction of plant genets in dense vegetation. Modules are defined as plant parts that would

160 be able to grow independently if separated from the genet, the plant individual derived from a

161 sexually produced seed (Harper 1977, Schmid 1990). The section of a creeping shoot between

162 two nodes and the leaf formed at the distal node was considered as a module in the case of $T$.

163 repens. All data are based on two 10-day harvest periods during early and late summer 2006

164 (June, August) at estimated peak biomass before mowing. Two legumes with an annual

165 overwintering life cycle, $T$. campestre and T. dubium, were only investigated during the first

166 harvest period because no adult plants were available in late summer.

167 In each plot where legumes were growing, five modules per species were randomly chosen

168 along transects divided into regular sections (of 50 and $25 \mathrm{~cm}$ length in large and small plots,

169 respectively). In the field, module height and canopy height of the immediately surrounding

170 vegetation were determined. Module number per genet was counted for species where genets

171 could be distinguished from each other. The selected modules were cut off near the ground,

172 put in sealed plastic bags and transported in a cool box to the laboratory. The following

173 standard protocol was used for further sample preparation. Stretched module length (=

174 maximum shoot length) and internode length of 3 to 5 internodes in the central part of the

175 main shoot axis were measured. Modules were separated into compartments (supporting

176 parts: stems and secondary axes; leaves; reproductive parts: inflorescences and fruits). 
177 Secondary axes, higher-order axes and inflorescences were counted. Phenology was assessed on a nine-part scale according to different stages of flower and fruit development. Three to ten (dependent on leaf size and number) fully expanded leaves from the upper module part were chosen, and leaf area was measured immediately as part of the biomass separation process (LI-3100 Area Meter, LI-COR, Lincoln, U.S.). Petioles and rachis of compound leaves were included in leaf area measurements.

All plant material was dried $\left(70^{\circ} \mathrm{C}, 48 \mathrm{~h}\right)$ and weighed. Leaf samples as well as the remaining plant compartments (= bulk samples per species and plot) were ground with a ball mill. Approximately $20 \mathrm{mg}$ of this material was analysed for carbon and nitrogen concentrations with an elemental analyzer (Vario EL Element Analyzer, Elementar, Hanau, Germany). Nitrogen $\left(\delta^{15} \mathrm{~N}\right)$ and carbon $\left(\delta^{13} \mathrm{C}\right)$ isotope ratios were measured from leaf material $(3 \mathrm{mg}$ and $0.8 \mathrm{mg}$, respectively) with an isotope-ratio mass spectrometer (Delta C prototype IRMS, Finnigan MAT); sample ratios of ${ }^{15} \mathrm{~N} /{ }^{14} \mathrm{~N}$ are given relative to the international standard for atmospheric $\mathrm{N}_{2}$, and sample ratios of ${ }^{13} \mathrm{C} /{ }^{12} \mathrm{C}$ refer to the VPDB standard for $\mathrm{C}$. Values are expressed in per-mil relative to the standards. To assess $\mathrm{N}_{2}$ fixation of legumes with the ${ }^{15} \mathrm{~N}$ natural abundance method (Amarger et al. 1979), Lolium perenne L. (sown as additional species into a small area of all large experimental plots; Roscher et al. 2008) and Taraxacum officinale Wiggers (included in the experimental species pool and occurring as a weed in near all plots where the species was not sown; Roscher et al. 2009) were used as non- $\mathrm{N}_{2}$-fixing reference species. Leaf material of these species collected during both harvest campaigns in all large plots, where these species were available, was analysed for $\delta^{15} \mathrm{~N}$. The ${ }^{15} \mathrm{~N}$ abundances in legumes and reference species were used to calculate the proportion of legume $\mathrm{N}$ derived from the atmosphere (pNdfa) as

$$
\mathrm{pNdfa}=\left(\delta^{15} \mathrm{~N}_{\text {ref }}-\delta^{15} \mathrm{~N}_{\text {legume }}\right) /\left(\delta^{15} \mathrm{~N}_{\text {ref }}-\mathrm{B}\right)
$$
(eq. 1), where $\delta^{15} \mathrm{~N}_{\text {ref }}$ and $\delta^{15} \mathrm{~N}_{\text {legume }}$ are the ${ }^{15} \mathrm{~N}$ abundances in the reference species and the $\mathrm{N}_{2}$ fixing 
202

legume species (Amarger et al. 1979, Högberg 1997). B values describing the $\delta^{15} \mathrm{~N}$ of the $\mathrm{N}_{2}$ 204 weighed.

fixing species when grown with $\mathrm{N}_{2}$ in air as the sole $\mathrm{N}$ source were set to the lowest detected $\delta^{15} \mathrm{~N}$ for each legume species (Hansen and Vinther 2001, Carlsson et al. 2009). Foliar $\delta^{15} \mathrm{~N}$ values of the reference species $L$. perenne and $T$. officinale varied depending on spatial location of the experimental plots at the field site (using block identity and geographic coordinates as explanatory terms) and decreased with sown species richness (Appendix Fig. S1 in Supplementary Material). The dependence on plot location may be due to spatial variation in soil $\delta^{15} \mathrm{~N}$ at the field site. Declining foliar $\delta^{15} \mathrm{~N}$ values with increasing species richness might indicate a shift in the uptake of different $\mathrm{N}$ forms, an increasing transfer of $\mathrm{N}$ from legumes to co-occurring plants or a larger amount of soil $\mathrm{N}$ deposited by legume plants via rhizodeposition or degradation of legume litter (Högberg 1997). Because the mechanisms causing a decrease in $\delta^{15} \mathrm{~N}$ values of reference species with increasing species richness or affecting their spatial variation across the field site equally apply to legumes themselves, pNdfa was only calculated if $\delta^{15} \mathrm{~N}$ values of reference species growing at the same plot were available. Therefore, small monoculture plots of legumes were excluded from these calculations. Differences in foliar $\delta^{15} \mathrm{~N}$ between the reference species were not statistically significant. Thus, pNdfa obtained with either L. perenne or T. officinale as reference species were used in cases where only one of these species was available and values were averaged in plots where both species could be sampled.

Community biomass was recorded in each plot in $20 \times 50 \mathrm{~cm}$ rectangles shortly before mowing. Two randomly allocated samples were taken in small plots, and four samples were harvested in large plots. Plant material was cut $3 \mathrm{~cm}$ above ground, dried $\left(70^{\circ} \mathrm{C}, 48 \mathrm{~h}\right)$ and

\section{Data analyses}


All trait values were averaged per species and plot for each harvest campaign. Derived variables for further analyses are summarized in Table 2. Measurements of $T$. fragiferum were excluded from all analyses because this species was extinct in a large number of plots (Table 1). Data were analysed with mixed-effects models using the nlme package of the statistical software R2.6.2 (R Development Core Team, http://www.R-project.org). Although the Jena Experiment has a factorial design based on gradients of species and plant functional group richness, the random species allocation to each mixture led to unbalanced occurrences of individual species in the experimental plots that violate the assumption of independence of errors. Mixed-effects models account for this non-independence of errors by modelling the covariance structure given by the random effects as grouping variable (Crawley 2002). Block and plot identity were entered as random effects in a nested sequence. Starting from a constant null model we added the fixed effects sequentially. Firstly, we fitted plant diversity as species richness separated into a monoculture vs. mixture contrast (Mo) and a log-linear term (SR), and functional group number (FG). Secondly, legume species identity (ID) was entered. In the following steps we fitted interaction terms between species identity and the experimental factors $(I D \times$ Mo, $I D \times$ SR, $I D \times F G)$, season $(J u n e$, August) and interaction terms between season and the previously mentioned terms. We applied the maximum likelihood method and used likelihood ratio (L) tests to assess the statistical significance of model improvement. In alternative models we changed the fitting order of the experimental factors SR and FG because of the slight non-orthogonality between them. However, both fitting sequences yielded very similar results. Furthermore, we tested whether plant functional group composition (presence and absence of grasses, small herbs and tall herbs) explained additional variation in trait values. Because we only rarely observed effects of these explanatory terms, we do not present the corresponding results. To test whether effects of species and functional group number on the values of legume traits operated in an indirect 
252

253

way via increasing the canopy height or community biomass, we fitted these plant community characteristics as covariates before the experimental treatments in a further set of models. $\mathrm{R}^{2}$ statistics for the mixed models were calculated based on likelihood-ratio test statistics comparing the log-likelihood of the model after fitting the explanatory terms with the loglikelihood of the model excluding these terms (Magee 1990).

Finally we explored functional traits (excluding performance indicators such as module biomass and traits characterising reproduction) with standardized principal components analysis (PCA). We used the respective constrained ordination technique, redundancy analysis (RDA), with different combinations of explanatory terms and covariates, i.e. (1) species identity, (2) community diversity (monoculture vs. mixture contrast, log-linear species richness, functional group number), (3) canopy height and community biomass, and (4) season in partial analyses to decompose the variation in functional traits explained by each set of explanatory variables following the procedure described in Borcard et al. (1992). In addition, we tested whether the differential responses of individual species explained a further proportion of variation and fitted interaction terms of species identity with community diversity and season. Block and plot identity were always entered as covariates and restricted Monte Carlo tests (999 permutations) were applied to assess the significance of explanatory terms. Ordination analyses were performed with CANOCO 4.5 (ter Braak and Šmilauer 2002).

\section{Results}

Aboveground plant traits of shoots and leaves and performance traits in terms of biomass and investment into reproduction differed significantly among the investigated legume species. In addition, the different legume species varied in their responses to increasing species and functional group number, i.e. plant diversity (Table 3, Appendix Table S1, S2). Community 
277

278

279

280

281

282

283

284

285

286

287

288

289

290

291

292

293

294

295

296

297

298

299

300

301

biomass increased from monocultures to mixtures $(\mathrm{L}=17.47, \mathrm{P}<0.001)$ and with increasing species richness of mixtures $(\mathrm{L}=4.69, \mathrm{P}=0.030)$. Community biomass before the first mowing was significantly higher than before the second mowing $(\mathrm{L}=31.08, \mathrm{P}<0.001)$.

Community biomass correlated positively with canopy height (May: $\mathrm{r}=0.712, \mathrm{P}<0.001, \mathrm{n}=$ 57; August: $\mathrm{r}=0.751, \mathrm{P}<0.001, \mathrm{n}=50$ ), which also increased from monocultures to mixtures $(\mathrm{L}=27.05, \mathrm{P}<0.001)$ and with increasing species richness of mixtures $(\mathrm{L}=6.86, \mathrm{P}$ $<0.001)$

In the following we (1) highlight the most significant effects of plant diversity on trait values of legumes, (2) assess whether the mechanism by which plant diversity affects trait values is primarily due to a diversity-induced change in canopy height or community biomass, or (3) whether there are additional significant direct effects of plant diversity on species-specific differences among legumes which cannot be explained by (2). We were particularly interested in trait variation potentially reflecting different strategies of light and nitrogen acquisition and retention among species.

\section{Legume positioning within the canopy (relative growth height)}

On average, relative growth height of legumes, i.e. module height compared with the surrounding vegetation, was significantly less than 1 in early summer (one-sample t-tests, $\mathrm{P} \leq$ 0.050) except for $O$. viciifolia with a relative growth height not significantly different from 1 $\left(t_{14}=0.547, P=0.593\right)$. In late summer relative growth height of $O$. viciifolia even exceeded canopy height (of all neighboring species) in mixtures $\left(\mathrm{t}_{14}=4.302, \mathrm{P}=0.001\right)$, while relative growth height of the other legumes was mostly close to $1(\mathrm{P}>0.05)$. Relative growth height generally decreased from monocultures to mixtures, which was primarily attributable to increasing canopy height and community biomass (Table 3; Fig. 1a, 2a, S2a). However, perspecies analyses showed that plant diversity affected relative growth height of all species 
except $O$. viciifolia not only via increased canopy height and community biomass (Table S2).

\section{Legume performance in terms of biomass and investment into reproduction}

305 On average, module mass of legumes did not change in response to plant diversity because 306 some species had lower module mass in monocultures than in mixtures and increased module 307 mass with increasing species richness of mixtures whereas other species showed the opposite 308 or no relationships (see significant interactions "ID $\times$ Mo", "ID $\times$ SR"; Table 3, S2; Fig. 1b, 309 S2b). Canopy height and community biomass affected module mass of legumes 310 independently of plant diversity, which had a significant direct effect even after fitting the 311 covariables. Module numbers per genet, counted for species with clearly distinguishable plant 312 genets only, were lower in mixtures than in monocultures, again irrespective of changes in 313 community characteristics described by the covariables (Table S1), however, this effect was 314 not significant in separate analyses for each individual species (Table S2).

315 Overall, the number of inflorescences per module decreased with increasing species richness, 316 but the response of individual species varied greatly (Table S1, S2). Flower or fruit 317 development was generally more advanced in monocultures than in mixtures of increasing 318 species richness (Table S1). This negative effect of mixture environment on reproductive 319 phenology was mainly due to increasing canopy height and community biomass.

\section{$321 \quad$ Shoot and leaf morphology}

322 Legumes growing in mixtures generally invested more biomass into supporting tissue (stems, 323 secondary axes) at the cost of leaf mass, resulting in lower leaf:stem ratios in mixtures of 324 increasing species richness (Table 3; Fig. 1c). Only two legume species, M. lupulina and $O$. 325 viciifolia, did not change the investment into stems and leaves when growing in mixtures or in 326 response to increasing species number in mixtures (Table S2). The number of secondary axes 
generally did not vary in response to community diversity, but individual species differed in their response to some degree (significant interaction "ID $\times$ Mo"; Table S1). Four species produced shoots with fewer secondary axes either in mixtures compared with monocultures or with increasing species number in mixtures (Table S2). Shoot length of all species except for O. viciifolia and $V$. cracca increased from monocultures to mixtures or with increasing species number in mixtures (Table 3, S2; Fig. 1d, S2d). The formation of longer shoots was mostly correlated with elongated internodes on the main axes (Table S1, S2). All species except $O$. viciifolia increased the SLA from monocultures to mixtures or with increasing species or functional group numbers in mixtures (Table 3, S2; Fig. 1e, S2e). Plant diversity effects on shoot and leaf morphology were due to increasing canopy height and community biomass, but significant interactions between species identity and plant diversity ("ID $\times$ Mo", “ID $\times$ SR",'ID $\times$ FG", Table 3, Fig. 2c-e) remained even after fitting these covariables. This suggested that variation of morphological traits in response to plant diversity differed among the studied legumes.

\section{Leaf nitrogen and isotopic signatures}

The relationship between mass-based leaf nitrogen and species richness largely depended on species identity (Table 3; Fig. 1f, S2f). Leaf nitrogen concentrations were either reduced (three legume species), increased (two legume species) or did not change in response to species or functional group richness (Table S2) and were not influenced by canopy height or community biomass.

Foliar $\delta^{15} \mathrm{~N}$ values of legumes declined from monocultures to mixtures, with increasing species numbers in mixtures and when mixtures were composed of species belonging to different functional groups (Table 3, Fig. 1g, S2g), but significant interaction terms with species identity indicated differential effects of plant diversity on foliar $\delta^{15} \mathrm{~N}$ values of the 
352

353

various legume species (Table S2). Although canopy height and community biomass had significant effects on foliar $\delta^{15} \mathrm{~N}$ values (Fig. 2g, Table 3), these variables only partly explained plant diversity effects. On average, foliar $\delta^{15} \mathrm{~N}$ values of legumes were significantly lower in early summer than in late summer, but these seasonal differences varied among species (Table S2). In contrast, foliar $\delta^{15} \mathrm{~N}$ values of two non- $\mathrm{N}_{2}$-fixing reference species did not differ significantly between early and late summer (paired t-tests $\mathrm{p}>0.05$; L. perenne $\delta^{15} \mathrm{~N}=1.91 \pm 0.84 \%$ SD, T. officinale $\delta^{15} \mathrm{~N}=1.90 \pm 1.09 \%$ ). Proportions of $\mathrm{N}$ derived from $\mathrm{N}_{2}$ fixation (pNdfa) calculated based on the ${ }^{15} \mathrm{~N}$ natural abundance method with $T$. officinale and L. perenne as reference species, where these reference species were available, differed significantly among legume species $(\mathrm{L}=44.15, \mathrm{P}<0.001)$. The proportion of $\mathrm{N}$ derived from $\mathrm{N}_{2}$ fixation increased with increasing species numbers in mixtures $(\mathrm{L}=10.42, \mathrm{P}=0.012$, Fig. 3 , and increasing functional group number $(\mathrm{L}=5.77, \mathrm{P}=0.016)$; it was higher in early summer than in late summer $(L=23.27, p<0.001$; June $0.80 \pm 0.16$, August $0.70 \pm 0.22$ averaged across species and plots).

Foliar $\delta^{13} \mathrm{C}$ values decreased from monocultures to mixtures and species-specific values became lower in mixtures of increasing species or functional group number in most legume species (Table 3; Fig. 1h, S2h) except for the tallest species $M . \times$ varia and O. viciifolia (Table S2). Unexpectedly, averaged across all species, foliar $\delta^{13} \mathrm{C}$ values decreased when foliar $\mathrm{N}$ concentrations increased (Pearson correlation coefficient for early summer: $\mathrm{r}=$ 0.412, $\mathrm{P}<0.001, \mathrm{n}=132$; for late summer: $\mathrm{r}=-0.260, \mathrm{P}=0.004, \mathrm{n}=119$ ), while significant correlations for individual species were rare. Relative module height as surrogate for legume positioning within the canopy was positively related to foliar $\delta^{13} \mathrm{C}$ values averaged across all species (Pearson correlation coefficient for early summer: $\mathrm{r}=0.540, \mathrm{P}<0.001, \mathrm{n}=132$; for late summer: $\mathrm{r}=0.527, \mathrm{P}<0.001, \mathrm{n}=119$ ) and was often correlated in analyses of individual species as well. 


\section{Nitrogen utilization (module biomass: $N$ ratio)}

379 Variation in biomass: $\mathrm{N}$ ratios at the whole-shoot level in response to plant diversity varied

380 largely among legume species (Table 3, Fig. 1i, S2i) with significant effects in nine species 381 (Table S2). Increasing canopy height and community biomass led to increased shoot 382 biomass: $\mathrm{N}$ ratios independent of variation in plant diversity (Fig. 2i).

\section{Patterns of seasonal variation}

Values of all traits except for inflorescence number per module differed between measurement dates (early June vs. August; Table 3, S1; Fig. S3). Relative module height, leaf:stem ratio, mass-based leaf nitrogen, foliar $\delta^{13} \mathrm{C}$ and $\delta^{15} \mathrm{~N}$ achieved larger values later in the growing season. In contrast, module mass, shoot length, SLA and module biomass:N ratios had larger values before first mowing. Seasonal variations in SLA and foliar $\delta^{13} \mathrm{C}$ were mediated by variation in community characteristics between early and late summer, while canopy height and community biomass only partly explained seasonal variation in other traits.

\section{Multiple trait analysis}

The three leading axes of the principal components analysis accounted for $67 \%$ of total variation in legume functional traits (first axis $29 \%$, second axis $22 \%$, third axis $16 \%$ ). The

396 first axis had high loadings for traits related to plant height, i.e. shoot length, internode length, 397 and module biomass: $\mathrm{N}$ ratios. This axis separated O. viciifolia from the other legumes. The

398 second axis was characterized by traits related to species positioning in the canopy, i.e. SLA, 399 foliar $\delta^{13} \mathrm{C}$ values, and relative module height, while the third axis accounted for variation in 400 mass-based leaf nitrogen and number of secondary axes per shoot. Redundancy analysis 401 (RDA) showed that functional traits were significantly related to the explanatory variables 
402

403

404

405

406

407

408

409

410

411

412

413

414

415

416

417

418

420

421

422

423

424

425

426

which were included in a model that accounted for $44.9 \%$ of the total variation. The partition into different sets of explanatory variables indicated a large effect of species identity (explaining $33.8 \%$ of variation) and a small, but significant effect of season (Fig. 4). While plant diversity and community characteristics together explained a significant proportion in trait variation, the decomposition of these terms gave evidence that main effects of plant diversity on legume trait combinations were largely explained by canopy height and community biomass. That is, by increasing canopy height and community biomass, plant diversity affected these traits indirectly. Interactions of species identity with community diversity and season explained an additional proportion of variation $(12.3 \%)$ leaving in total $42.8 \%$ of unexplained variation. These results underscore the differential responses of legume species to community diversity and across season.

\section{Discussion}

Variation in functional traits to optimize resource capture, to compete with neighbors and finally to produce seed or vegetative offspring are of major importance for the adjustment of plants to their abiotic and biotic environment (Schlichting 1986, Sultan 1995). It is known from many studies that plant species are plastic for numerous ecologically important traits including morphology, physiology, anatomy, development and reproduction (Bradshaw 1965, Sultan 2000, Valladares et al. 2007). These studies also reported large interspecific differences in trait variation, and correlations between traits may vary in different environments (Schlichting 1989). Therefore the study of a large set of traits is required to assess trait variation in relation to complex environmental changes, such as variation in plant diversity and species composition, which affects the availability of multiple resources at the same time.

In our study, we focused on traits measured on aboveground plant organs which are known as 
427 indicators for strategies of light and nitrogen capturing, because these resources are among the 428 most limiting factors for plant growth in temperate grassland. The complementarity 429 hypothesis in biodiversity research suggests that positive diversity-productivity relationships 430 are related to a more complete use of available resources due to diversity in plant functional 431 characteristics and niche differentiation among species (Tilman et al. 1997). Competition for 432 light and nutrients increases at higher productivity levels. To assess to which extent 433 significant effects of plant diversity on trait variation of legumes were mechanistically 434 explained by diversity-induced increases of canopy height and community biomass, i.e. 435 generalised light competition, we compared the results of analyses unadjusted for these 436 covariables with results of analyses adjusted for these covariables. When in addition to the 437 indirect effect via the two covariables there was a "residual" direct effect of diversity, other 438 covariables which were not measured and thus could not be included in the analysis must 439 have been mechanistically involved in the effect. These residual direct effects were obviously 440 not related to generalised light competiton but mostly represented differential effects of plant 441 diversity on the different legumes species and were probably related to increasing 442 complementarity among legumes in resource acquisition and retention.

\section{Nitrogen acquisition}

445 Because of their ability to fix $\mathrm{N}_{2}$ symbiotically, legume species are less reliant on growth446 limiting soil nitrogen resources than other grassland species. However, the energy-consuming

447 symbiotic $\mathrm{N}_{2}$ fixation may be suppressed when alternative $\mathrm{N}$ sources decrease the need for 448 symbiotically fixed N (Hartwig 1998, Carlsson and Huss-Danell 2003). Because the presence 449 of non-fixing plants that deplete soil mineral nitrogen, or even directly receive nitrogen fixed 450 by legumes by uptake of root exudates or from mycorrhizal links to legumes (Paynel et al. 451 2001, Govindarajulu et al. 2005), increases from legume monocultures to mixtures and in 
452 mixtures with increasing species and functional group numbers, it is likely that legumes

453 become more dependent on their symbiotic $\mathrm{N}$ source with increasing plant diversity. The 454 application of the ${ }^{15} \mathrm{~N}$ natural abundance method with non- $\mathrm{N}_{2}$-fixing reference species $(L$. 455 perenne, $T$. officinale) to assess proportions of legume- $\mathrm{N}$ derived from $\mathrm{N}_{2}$ fixation (pNdfa) 456 provided consistent evidence that legume dependence on symbiotic $\mathrm{N}$ source increased with 457 increasing plant diversity. This variation was only partly driven by increasing community 458 productivity and indicated that interactions between legumes and non-legumes were 459 modulated through other plant-diversity related mechanisms (Fig. 3). In spite of this overall 460 stimulating effect of plant diversity on $\mathrm{N}_{2}$ fixation, $\mathrm{pNdfa}$ values varied among legume 461 species and were particularly high in the short-lived legumes T. campestre and T. dubium 462 which probably have a lower ability to compete with established perennial species for soil 463 nitrogen. The higher proportions of $\mathrm{N}$ derived from $\mathrm{N}_{2}$ fixation in early summer - when 464 experimental communities reached peak biomass - than in late summer before the second 465 mowing — which correlated with higher leaf nitrogen concentrations and lower biomass: $\mathrm{N}$ 466 ratios at the module level — gave further indication that legumes increased their reliance on $467 \mathrm{~N}_{2}$ fixation when competition for soil $\mathrm{N}$ was large.

\section{Light acquisition}

470 Our comparison of canopy height and plant height of individual legumes suggested that their 471 access to direct insolation decreased with increasing plant community diversity, although we 472 could not characterise the light climate experienced by the investigated plant individuals. All 473 species except for the tallest, $O$. viciifolia, did not reach maximum canopy height in mixtures 474 in early summer, whereas they did so in late summer (Fig. S2a, S3a). Canopy profiles are 475 characterised by an exponential decrease of photosynthetic active radiation (Wacker et al. 476 2009) and changes in spectral light quality with a lower red to far red ratio deeper in the 
477

478

479

480

481

482

canopy (Jones 1992). The disproportionate share of light obtained by larger plants increases the probability that smaller plants are outcompeted by shading (Weiner 1990). Our measurements at the whole-shoot and leaf level revealed that legume species in mixtures usually possessed typical strategies to tolerate or avoid lower light availability to a certain degree. They formed longer shoots with elongated internodes, reduced branching and invested more biomass into supporting tissue at the cost of leaf mass, all mechanisms known to enhance the chance to overtop neighbors in dense canopies (Smith 1982, Poorter and Nagel 2000). In addition, legumes generally increased their specific leaf area with increasing plant diversity, which is again a typical response of shaded plants (Corré 1983, Evans and Poorter 2001). Although variation in these traits differed among legume species, all of them except for the tall $O$. viciifolia increased shoot and internode length, had a lower leaf:stem ratio and increased SLA in relation to increasing species and functional group numbers (see Table 3).

A large amount of variation in these light acquisition traits probably represented generalized competiton for light which was independent of the particular species contributing to it because it could be explained by the covariables canopy height and community biomass. Nevertheless, significant proportions of species-specific responses were attributable to residual direct effects of plant diversity not related to these covariables, suggesting that in addition to a generalized component of light competiton there were also more specific components encapsulated in our plant diversity factors species richness and functional group number. Because these effects were different for the different legume species, they were probably related to complementary strategies of light acquisition. However, not all shadeavoidance reactions may reflect adaptive strategies, i.e. they may not always increase light acquisition and thus be mal-adaptive. A typical case occurs when the shade-avoidance reaction does not allow plant individuals to overtop their neighbors or reach canopy height (Weinig 2000). Although all legume species established successfully in all experimental plots 
in the year of sowing in the Jena Experiment (unpubl. data), 4 years after sowing the smallest legume species with an annual overwintering or biannual life cycle, such as M. lupulina, $T$. campestre and T. dubium as well as the creeping $T$. fragiferum, went extinct in many experimental mixtures of higher species richness (see Table 1). This extinction is probably due to their non-sufficient genetic predisposition for adjustment or due to resource limitation of these species to adapt to canopy shade in multi-species mixtures. Even if smaller species may possess a larger trait variation, it might not be sufficient to increase competitiveness in plant communities of increasing diversity (Thein et al. 2008).

Foliar $\delta^{13} \mathrm{C}$ values can give further information about plant positioning in the canopy. A wide range of physiological and biochemical processes affect isotopic composition of bulk samples: i) $\mathrm{CO}_{2}$ source, ii) ratio of intercellular to ambient $\mathrm{CO}_{2}$ concentrations $\left(\mathrm{C}_{\mathrm{i}} / \mathrm{C}_{\mathrm{a}}\right)$ during assimilation, iii) metabolism and biosynthesis of carbon compounds, iv) cellular carbon budgets (Farquhar et al. 1989, Dawson et al. 2002). Thus, the carbon isotope composition of plants is jointly affected by the abiotic (e.g. irradiance, soil moisture, temperature, nitrogen nutrition) and biotic (e.g. leaf physiology, canopy height) environment of individual plants. In contrast to an expected positive correlation between $\delta^{13} \mathrm{C}$ values and leaf nitrogen concentrations under a nitrogen limitation of $\mathrm{C}$ assimilation (Evans 1989), these variables varied largely independently at the species level in our study. Instead, plant canopy characteristics determined variation in foliar $\delta^{13} \mathrm{C}$ values, although this relationship may have several causes. In contrast to studies of foliar $\delta^{13} \mathrm{C}$ in previous biodiversity experiments (Caldeira et al. 2001, Jumpponen et al. 2005), canopy profiles measured in a 60-species plot in our experiment showed an increase in $\mathrm{CO}_{2}$ concentrations with increasing canopy depth (unpubl. data). This $\mathrm{CO}_{2}$ enrichment in lower canopies might be related to a decrease in $\delta^{13} \mathrm{C}$ values of source $\mathrm{CO}_{2}$ because soil respiration produces $\mathrm{CO}_{2}$ with carbon isotope ratios similar to the substrate (Peterson and Fry 1987) and may affect foliar $\delta^{13} \mathrm{C}$ of species growing in the 
canopy (Farquhar et al. 1989, da Silveira et al. 1989). However, light availability and air humidity in lower canopy levels may also control $\mathrm{C}_{\mathrm{i}} / \mathrm{C}_{\mathrm{a}}$ ratios via stomata aperture and hence affect ${ }^{13} \mathrm{C} /{ }^{12} \mathrm{C}$ ratios in leaf material. Foliar $\delta^{13} \mathrm{C}$ values correlated with relative growth height of legume modules and were significantly higher in late summer when legumes reached a higher relative height than in early summer (Fig. S3h). In contrast, we found no diversity effects on foliar $\delta^{13} \mathrm{C}$ values of the tallest legumes $M . \times$ varia and $O$. viciifolia indicating that light availability was a major control of carbon isotope discrimination, although we cannot exclude effects of source-air isotopic composition.

\section{Fitness consequences}

In our experiment, legumes mostly remained or even increased their performance at the module level assessed as module biomass in communities of increasing diversity. At the same time, plant genets often consisted of fewer modules in more diverse plant communities (except for O. viciifolia, T. pratense), indicating a decreasing performance at the genet level. Biomass allocation to reproductive compartments usually depends on plant size (Harper 1977). Reproductive structures have high resource costs and allocation into reproduction is generally greater under resource excess (Bloom et al. 1985). Therefore the observed reduction of inflorescence numbers in several legumes is not surprising, because it is likely that lower light availability — correlated with a decrease in legume module biomass (Table 3) — also affected the investment of legume species into reproduction.

\section{Conclusions}

So far, effects of community diversity on plant functional traits and their variation have received little attention although it is known that variation in physiological, morphological and life-history traits may alter direct and indirect interactions of organisms with their abiotic 
and biotic environment (Callaway et al. 2003, Miner et al. 2005). Our study provided evidence for highly consistent effects of plant diversity on plant traits. Trait variation in particular of traits reflecting strategies for light acquisition were partly attributable to diversity-related changes in community characteristics in terms of canopy height and biomass production. However, plant diversity beyond these community characteristics was mainly responsible for species-specific trait variation of different legume species.

In our study we cannot differentiate whether variation of functional traits in legume species growing in plant communities of different diversity is exclusively due to phenotypic responses or whether different growing conditions led to local genetic differentiation at plotscale, although each species was established with identical seed populations in all plots (Roscher et al. 2004). In addition, the potential plastic response of a species may be larger than what was observed, which might have been limited by resource availability (van Kleunen and Fischer 2005); and the number of replicates of particular legume species at each speciesrichness level was often small. Nevertheless, our study shows that the investigated legume species are neither redundant in their functional characteristics nor in the variation of these traits in relation to plant diversity. This is in line with previous studies at larger scales (Díaz et al. 2004). The uniqueness of species behavior shows that a priori classifications into functional groups are limited in their usefulness to elucidate biodiversity effects on ecosystem processes (Wright et al. 2005, McGill et al. 2006). Therefore, it is important to also consider potential particularities of individual species and interactions between individual species to better understand processes measured at the community level.

\section{Acknowledgements}

The Jena Experiment is funded by the German Science Foundation (FOR 456) with additional support from the Max Planck Society and the Friedrich Schiller University Jena. We thank all 
577 people helping with the management of the experiment, especially the gardeners and many

578 student helpers. We gratefully acknowledge U. Wehmeier, S. Hengelhaupt, A. Höfer, C.

579 Jeschke, A. Mraja and N. Streit for their help during harvest and sample preparation. I. Hilke

580 and H. Geilmann conducted chemical and stable isotope analyses. We acknowledge J.

581 Schumacher for advice on statistical analyses. Finally, we thank four anonymous referees and

582 P. Reich for their valuable comments which helped to improve the manuscript.

References

585

586

Amarger N, Mariotti A, Mariotti F, Durr JC, Bourguignon C, Lagacherie B (1979) Estimate of symbiotically fixed nitrogen in field grown soybeans using variations in ${ }^{15} \mathrm{~N}$ natural abundance. Plant Soil 52:269-280

Balvanera P, Pfisterer AB, Buchmann N, He J-S, Nakashizuka T, Raffaelli D, Schmid B (2006) Quantifying the evidence for biodiversity effects on ecosystem functioning and services. Ecol Lett 9:1146-1156

Borcard D, Legendre P, Drapeau P (1992) Partialling out the spatial component of ecological variation. Ecology 73:1045-1055

Bloom AJ, Chapin FS, Mooney HA (1985) Resource limitation in plants - an economic analogy. Annu Rev Ecol Syst 16:363-392

Bradshaw AD (1965) Evolutionary significance of phenotypic plasticity in plants. Adv Genet

$$
13: 115-155
$$

Caldeira MC, Ryel RJ, Lawton JH, Pereira JS (2001) Mechanisms of positive biodiversityproduction relationships: insights provided by $\delta^{13} \mathrm{C}$ analysis in experimental Mediterranean grassland plots. Ecol Lett 4:439-443

Callaway RM, Pennings SC, Richards CL (2003) Phenotypic plasticity and interactions among plants. Ecology 84:1115-1128 
Roscher et al.

602 Callaway RM (2007) Positive interactions and interdependence in plant communities. $603 \quad$ Springer, Dordrecht

604 Cardinale BJ, Wright JP, Cadotte MW, Carroll JA, Hector A, Srivastava DS, Loreau M, Weis 605 JJ (2007) Impacts of plant diversity on biomass production increase through time because 606 of species complementarity. Proc Natl Acad Sci USA 104:18123-18128

607 Carlsson G, Huss-Danell K (2003) Nitrogen fixation in perennial forage legumes in the field. 608 Plant Soil 253:353-372

609 Carlsson G, Palmborg C, Jumpponen A, Scherer-Lorenzen M, Högberg P, Huss-Danell K 610 (2009) $\mathrm{N}_{2}$ fixation in three perennial Trifolium species in experimental grasslands of varied 611 plant species richness and composition. Plant Ecol 205:87-104

612 Chiariello NR, Gulmon S (1991) Stress effects on plant reproduction. In: Mooney HA, 613 Winner WE, Pell EJ, Chu E (eds) Response of plants to multiple stresses. Academic Press, $614 \quad$ San Diego, pp 161-188

615 Corré WJ (1983) Growth and morphogenesis of sun and shade plants. I. The influence of light 616 intensity. Acta Bot Neerl 32:49-62

617 Crawley MJ (2002) Statistical computing. An introduction to data analysis using S-Plus. John $618 \quad$ Wiley \& Sons Ltd., Chichester

619 da Silveira L, Sternberg M, Mulkey SS, Wright SJ (1989) Ecological interpretation of leaf 620 carbon isotope ratios: influence of respired carbon dioxide. Ecology 70:1317-1324

621 Dawson TE, Mambelli S, Plamboeck AH, Templer PH, Tu KP (2002) Stable isotopes in plant 622 ecology. Annu Rev Ecol Syst 33:507-559

623 Díaz S, Cabido M (2001) Vive la différence: plant functional diversity matters to ecosystem 624 processes. Trends Ecol Evol 16:646-655

625 Díaz S, Hodgson JP, Thompson K, Cabido M, Cornelissen C, Jalili A, Montserrat-Martí G, 626 Grime JP, Zarrinkamar F, Asri Y, Band SR, Basconcelo S, Castro-Díez P, Funes G, 
Roscher et al.

Hamzehee B, Khoshnevi M, Pérez-Harguindeguy N, Pérez-Rontomé MC, Shirvany FA, Vendramini F, Yazdani S, Abbas-Azimi R, Bogaard A, Boustani S, Charles M, Dehghan M, de Torres-Espuny L, Falczuk V, Guerrero-Campo J, Hynd A, Jones G, Kowsary E, P, Zak MR (2004) The plant traits that drive ecosystems: evidence from three continents. J Veg Sci 15:295-304

633 Ellenberg H (1988) Vegetation ecology of Central Europe. Cambridge University Press, 634 Cambridge

Evans JR (1989) Photosynthesis and nitrogen relationships in leaves of $\mathrm{C}_{3}$ plants. Oecologia 78:9-19

Evans JR, Poorter H (2001) Photosynthetic acclimation of plants to growth irradiance: the relative importance of specific leaf area and nitrogen partitioning in maximizing carbon gain. Plant Cell Environ 24:755-767

640 Farquhar GD, Ehleringer J, Hubick KT (1989) Carbon isotope discrimination and photosynthesis. Ann Rev Plant Physiol Plant Mol Biol 40:503-537

642 Govindarajulu M, Pfeffer PE, Jin H, Abubaker J, Douds DD, Allen JW, Bücking H, Lammers PJ, Shachar-Hill Y (2005) Nitrogen transfer in the arbuscular mycorrhizal symbiosis. Nature 435:819-823

Hansen JP, Vinther FP (2001) Spatial variability of symbiotic $\mathrm{N}_{2}$ fixation in grass-white clover pastures estimated by the ${ }^{15} \mathrm{~N}$ isotope dilution method and the natural ${ }^{15} \mathrm{~N}$ abundance method. Plant Soil 230:257-266

649 Hartwig UA (1998) The regulation of symbiotic $\mathrm{N}_{2}$ fixation: a conceptual model of $\mathrm{N}$ 650 feedback from the ecosystem to the gene expression level. Perspect Plant Ecol Evol Syst 651 $1: 92-120$ 
652 Hector A, Bazeley-White E, Loreau M, Otway S, Schmid B (2002) Overyielding in grassland 653 communities: testing the sampling effect hypothesis with replicated biodiversity $654 \quad$ experiments. Ecol Lett 5:502-511

655 Högberg P (1997) ${ }^{15} \mathrm{~N}$ natural abundance in soil-plant systems. New Phytol 137:179-203

656 Hooper DU, Chapin FS, Ewel JJ, Hector A, Inchausti P, Lavorel S, Lawton JH, Lodge DM, 657 Loreau M, Naeem S, Schmid B, Setälä H, Symstad AJ, Vandermeer J, Wardle DA (2005) 658 Effects of biodiversity on ecosystem functioning: A consensus of current knowledge. Ecol $659 \quad$ Monogr 75:3-35

660 Jolliffe PA (2000) The replacement series. J Ecol 88:371-385

661 Jones HG (1992) Plants and microclimate. A quantitative approach to environmental plant 662 physiology. Cambridge University Press, Cambridge.

663 Jumpponen A, Mulder CPH, Huss-Danell K, Högberg P (2005) Winners and losers in 664 herbaceous plant communities: insights from foliar carbon isotope composition in 665 monocultures and mixtures. J Ecol 93:1136-1147

666 Kluge G, Müller-Westermeier G (2000) Das Klima ausgewählter Orte der Bundesrepublik 667 Deutschland: Jena. Ber Deutsch Wetterdienstes 213:1-290

668 Lorentzen S, Roscher C, Schumacher J, Schulze E-D, Schmid B (2008) Species richness and 669 identity affect the use of aboveground space in experimental grasslands. Perspect Plant $670 \quad$ Ecol Evol Syst 10:73-87

671 Magee L (1990) $\mathrm{R}^{2}$ measures based on Wald and likelihood joint significance tests. Am $672 \quad$ Statist $44: 250-253$

673 Marschner H (1995) Mineral nutrition of higher plants. Academic Press, London

674 McConnaughay KDM, Coleman JS (1999) Biomass allocation in plants: ontogeny or 675 optimality? A test along three resource gradients. Ecology 80:2581-2593 
676 McGill BJ, Enquist BJ, Weiher E, Westoby M (2006) Rebuilding community ecology from 677 functional traits. Trends Ecol Evol 21:178-185

678 Miner BG, Sultan SE, Morgan SG, Padilla DK, Relyea RA (2005) Ecological consequences

679 of phenotypic plasticity. Trends Ecol Evol 20:685-692

680 Oelmann Y, Wilcke W, Temperton VM, Buchmann N, Roscher C, Schumacher J, Schulze E681 D, Weisser WW (2007) Soil and plant nitrogen pools as related to plant diversity in an 682 experimental grassland. Soil Sci Soc Am J 71:720-729

683 Palmborg C, Scherer-Lorenzen M, Jumpponen A, Carlsson G, Huss-Danell K, Högberg P 684 (2005) Inorganic soil nitrogen under grassland plant communities of different species 685 composition and diversity. Oikos 110:271-281

686 Paynel F, Murray PJ, Cliquet JB (2001) Root exudates: a pathway for short-term N transfer 687 from clover and ryegrass. Plant Soil 229:235-243

688 Peterson BJ, Fry B (1987) Stable isotopes in ecosystem studies. Annu Rev Ecol Syst 18:293$689 \quad 320$

690 Poorter H, Nagel O (2000) The role of biomass allocation in the growth response of plants to 691 different levels of light, $\mathrm{CO}_{2}$, nutrients and water: a quantitative review. Aust J Plant $692 \quad$ Physiol 27:595-607

693 Roscher C, Schumacher J, Baade J, Wilcke W, Gleixner G, Weisser WW, Schmid B, Schulze 694 E-D (2004) The role of biodiversity for element cycling and trophic interactions: an 695 experimental approach in a grassland community. Basic Appl Ecol 5:107-121

696 Roscher C, Schumacher J, Weisser WW, Schmid B, Schulze E-D (2007) Detecting the role of 697 individual species for overyielding in experimental grassland communities composed of 698 potentially dominant species. Oecologia 154:535-549

699 Roscher C, Schumacher J, Weisser WW, Schulze E-D (2008) Genetic identity affects species 700 performance in grasslands of different plant diversity: an experiment with Lolium perenne 
Roscher et al. cultivars. Ann Bot 102:113-125

702

703

704

705

706

707

708

709

710

711

712

713

714

715

716

717

718

Roscher C, Beßler H, Oelmann Y, Engels C, Wilcke W \& Schulze E-D (2009) Resources, recruitment limitation and invader species identity determine pattern of spontaneous invasion in experimental grasslands. J Ecol 97:32-47

Schlichting CD (1986) The evolution of phenotypic plasticity in plants. Annu Rev Ecol Syst 17:667-693

Schlichting CD (1989) Phenotypic plasticiy in Phlox. II. Plasticity of character correlations. Oecologia 78:496-501

Schmid B (1990) Some ecological and evolutionary consequences of modular organization and clonal growth in plants. Evol Trends Plants 4:25-34

Smith H (1982) Light quality, photoperception, and plant strategy. Ann Rev Plant Physiol $33: 481-518$

Spehn EM, Joshi J, Schmid B, Diemer M, Körner C (2000) Above-ground resource use increases with plant species richness in experimental grassland ecosystems. Funct Ecol $14: 326-337$

Spehn EM, Scherer-Lorenzen M, Schmid B, Hector A, Caldeira MC, Dimitrakopoulos PG, Finn JA, Jumpponen A, O`Donnovan G, Pereira JS, Schulze E-D, Troumbis AY, Körner C (2002) The role of legumes as a component of biodiversity in a cross-European study of grassland biomass nitrogen. Oikos 98:205-218

Sultan SE (1995) Phenotypic plasticity and plant adaptation. Acta Bot Neerl 44:363-383

Sultan SE (2000) Phenotypic plasticity for plant development, function and life history. Trends Plant Sc 5:537-542

ter Braak CJF, Šmilauer P (2002) CANOCO reference manual and CanoDraw for Windows user's guide: software for canonical community ordination (version 4.5). Ithaca 
Tilman D, Knops J, Wedin D, Reich P, Ritchie M, Siemann E (1997) The influence of functional diversity and composition on ecosystem processes. Science 277:1300-1302

Thein S, Roscher C, Schulze E-D (2008) Effects of trait plasticity on aboveground biomass production depend on species identity in experimental grasslands. Basic Appl Ecol 9:475484

Valladares F, Gianoli E, Gómez JM (2007) Ecological limits to plant phenotypic plasticity. New Phytol 176:749-763

van Kleunen M, Fischer M (2005) Constraints on the evolution of adaptive phenotypic plasticity in plants. New Phytol 166:49-60

van Ruijven J, Berendse F (2003) Positive effects of plant species diversity on productivity in the absence of legumes. Ecol Lett 6:170-175

Violle C, Navas M-L, Vile D, Kazakou E, Fortunel C, Hummel I, Garnier E (2007) Let the concept of trait be functional! Oikos 116:882-892

Wacker L, Baudois O, Eichenberger-Glinz S, Schmid B (2009) Effects of plant species richness on stand structure and productivity. J Plant Ecol 2:95-106

Walker B, Kinzig A, Langridge J (1999) Plant attribute diversity, resilience, and ecosystem function: the nature and significance of dominant and minor species. Ecosystems 2:95-113

Weiner J (1990) Asymmetric competition in plant populations. Trends Ecol Evol 5:360-364

Weinig C (2000) Plasticity versus canalization: population differences in the timing of shadeavoidance responses. Evolution 54:441-451 Conventional functional classification schemes underestimate the relationships with ecosystem functioning. Ecol Lett 9:111-120 
Roscher et al.

749

750

751

752

753

754

755

756

757

758

759

760

761

762

763

764

765

766

767

768

769

770

771

772

773

Figure captions

Figure 1: Trait values plotted against sown species number. Trait values per species are averaged across different plots and season (June, August) for each species-richness level. Each regression line represents a legume species. For species symbols and line styles see Fig. 3.

Figure 2: Trait values plotted against canopy height including values measured in June (before first mowing) and August (before second mowing). Each regression line represents a legume species. For line styles see Fig. 3.

Figure 3: Proportion of $\mathrm{N}$ derived from $\mathrm{N}_{2}$ fixation (pNdfa) based on the ${ }^{15} \mathrm{~N}$ natural abundance method plotted against sown species number. Values per species are averaged across different plots and season (June, August) for each species-richness level. Each regression line represents a legume species.

Figure 4: Summary of Redundancy Analysis (RDA) using different sets of explanatory variables in partial analyses to decompose their effects on legume trait variation. For each set of explanatory variables being species identity, season and plant community (separated into diversity and canopy height and community biomass, respectively) the proportion of explained trait variation, F ratio statistics and P values obtained by Monte Carlo tests (999 permutations) are shown. Shared variation indicates the proportion of explained variability that cannot be attributed uniquely to a certain set of predictor variables. An additional proportion of variation may be explained by differential responses of individual species (interactions of species identity with community diversity and season). 
Roscher et al.

Figure 1

(a)

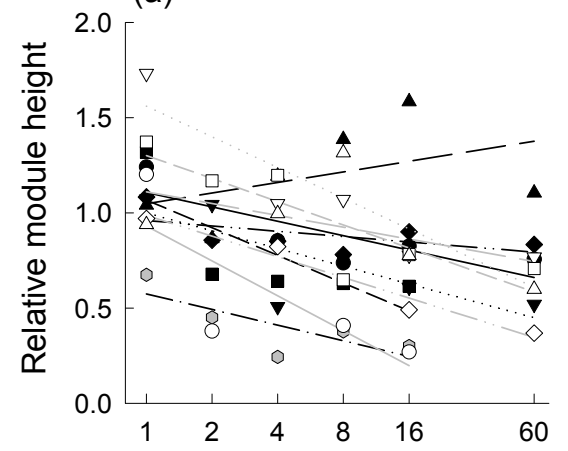

(d)

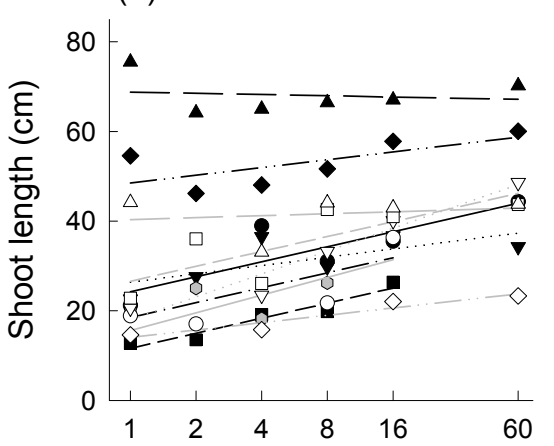

(g)

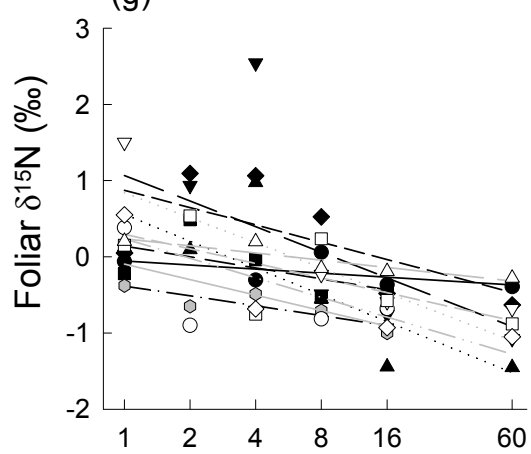

(b)

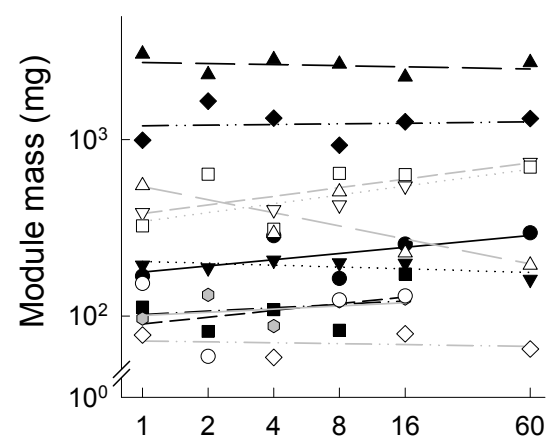

(e)

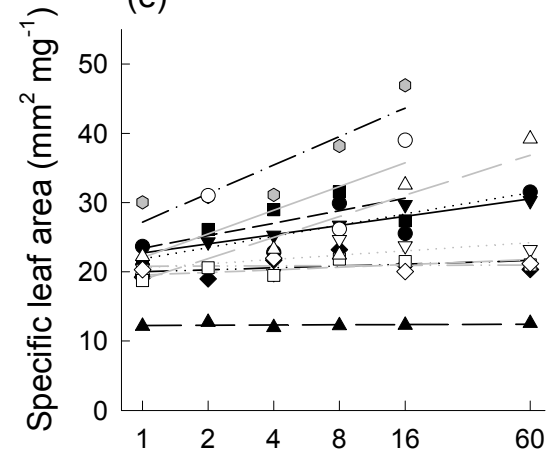

(h)

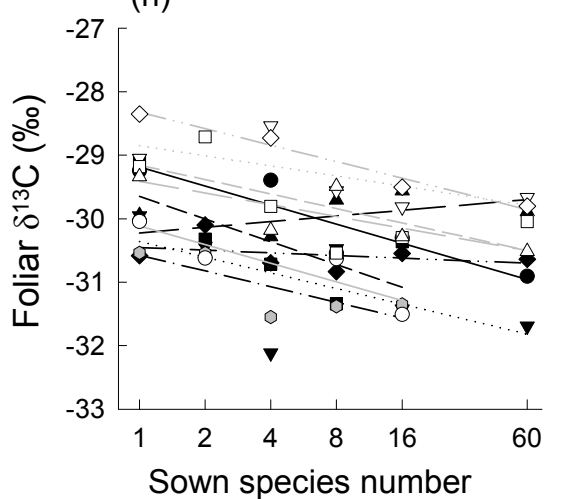

(c)

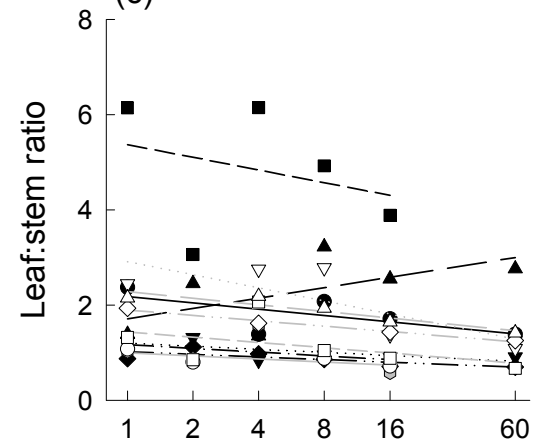

(f)

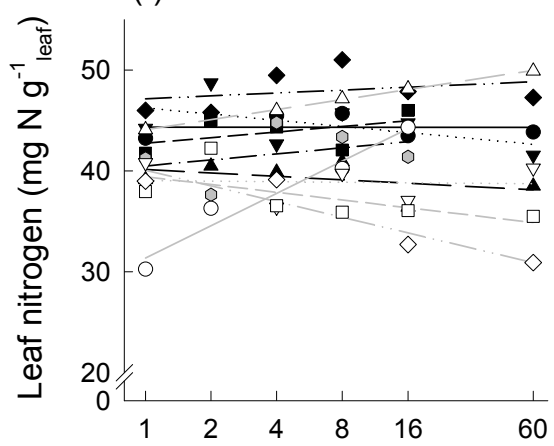

(i)

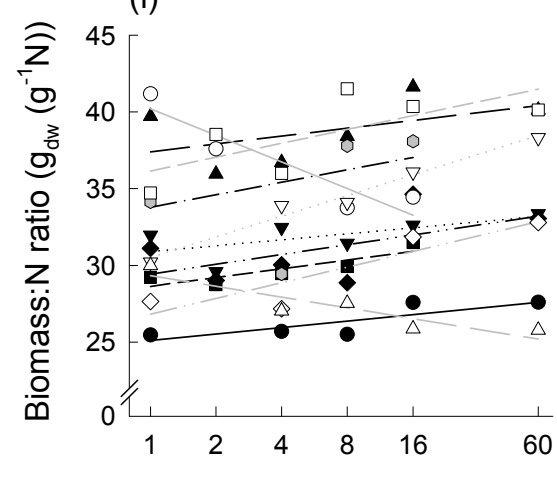


Roscher et al.

Figure 2

(a)

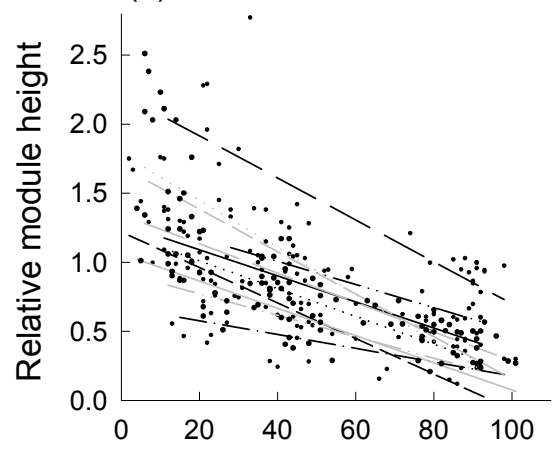

(d)

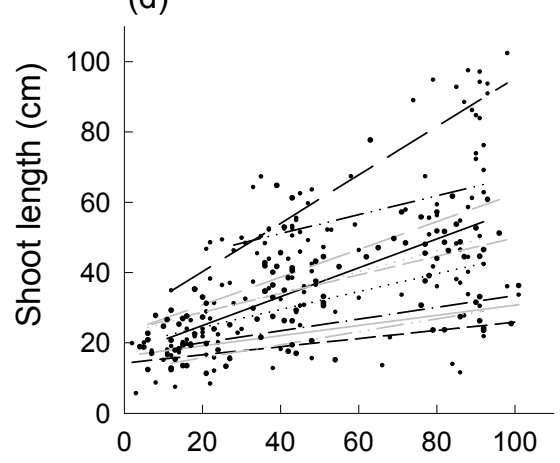

(g)

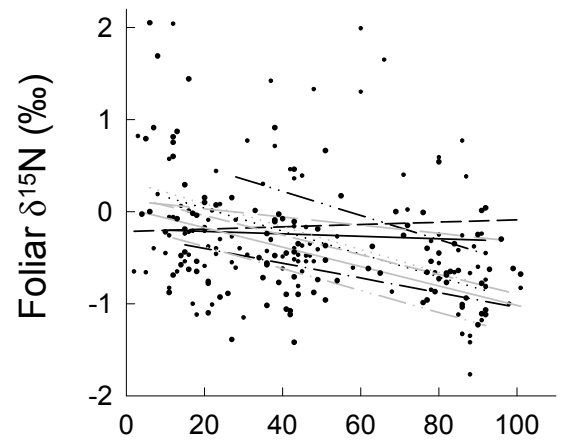

(b)

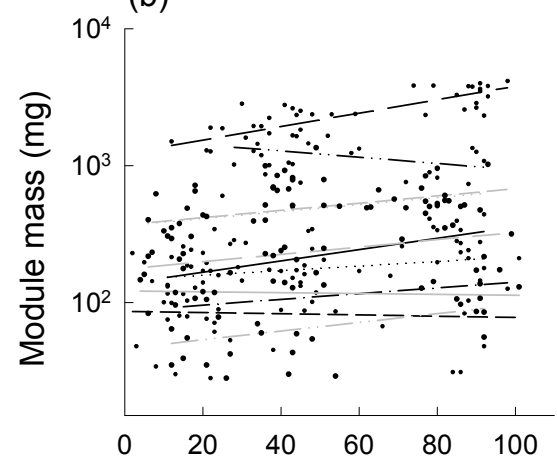

(e)

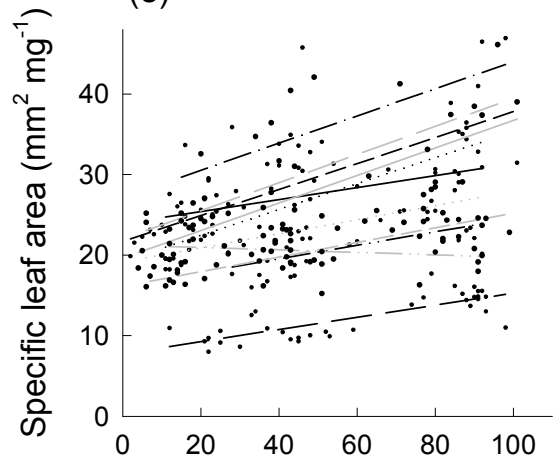

(h)

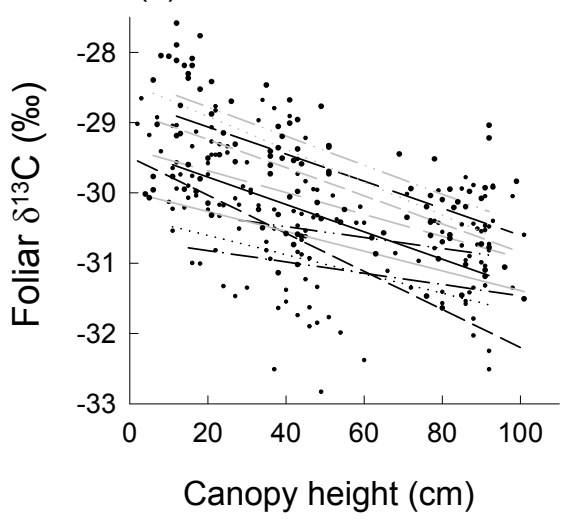

(c)

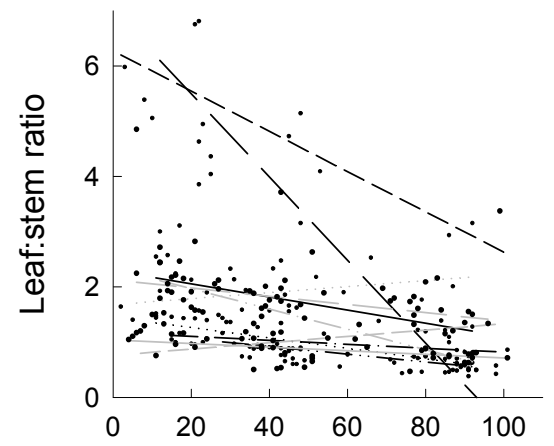

(f)

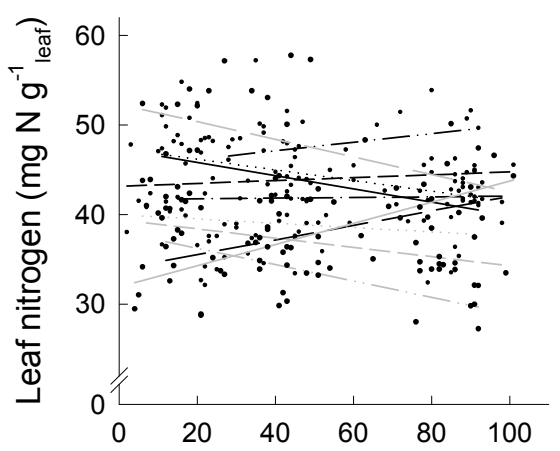

(i)

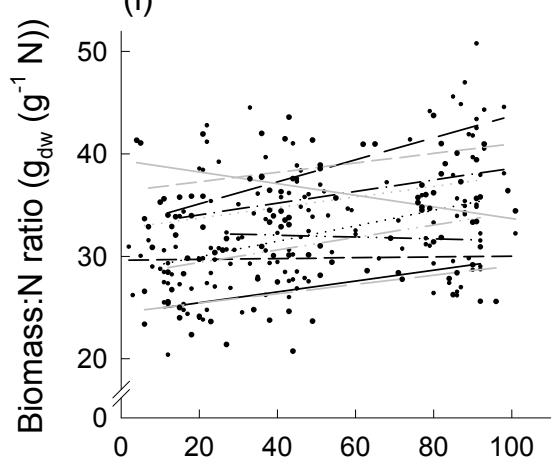


Roscher et al.

Figure 3

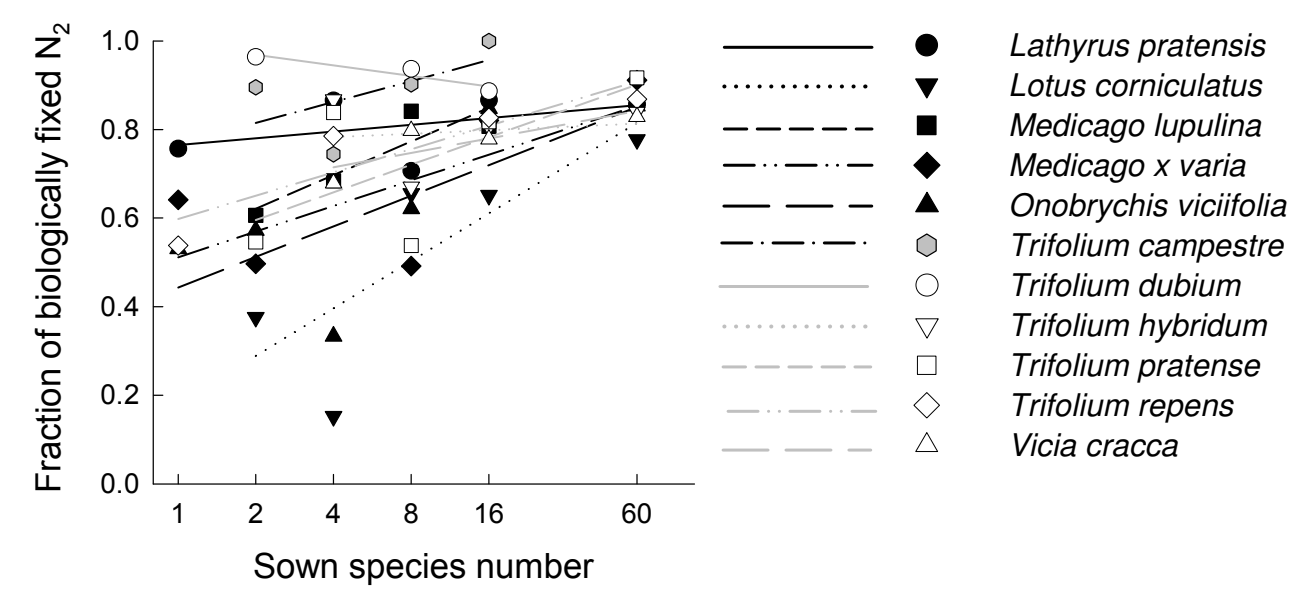


Roscher et al.

Figure 4

Explained variation (main effects $=44.9 \%$, including interactions $=57.2 \%$ )

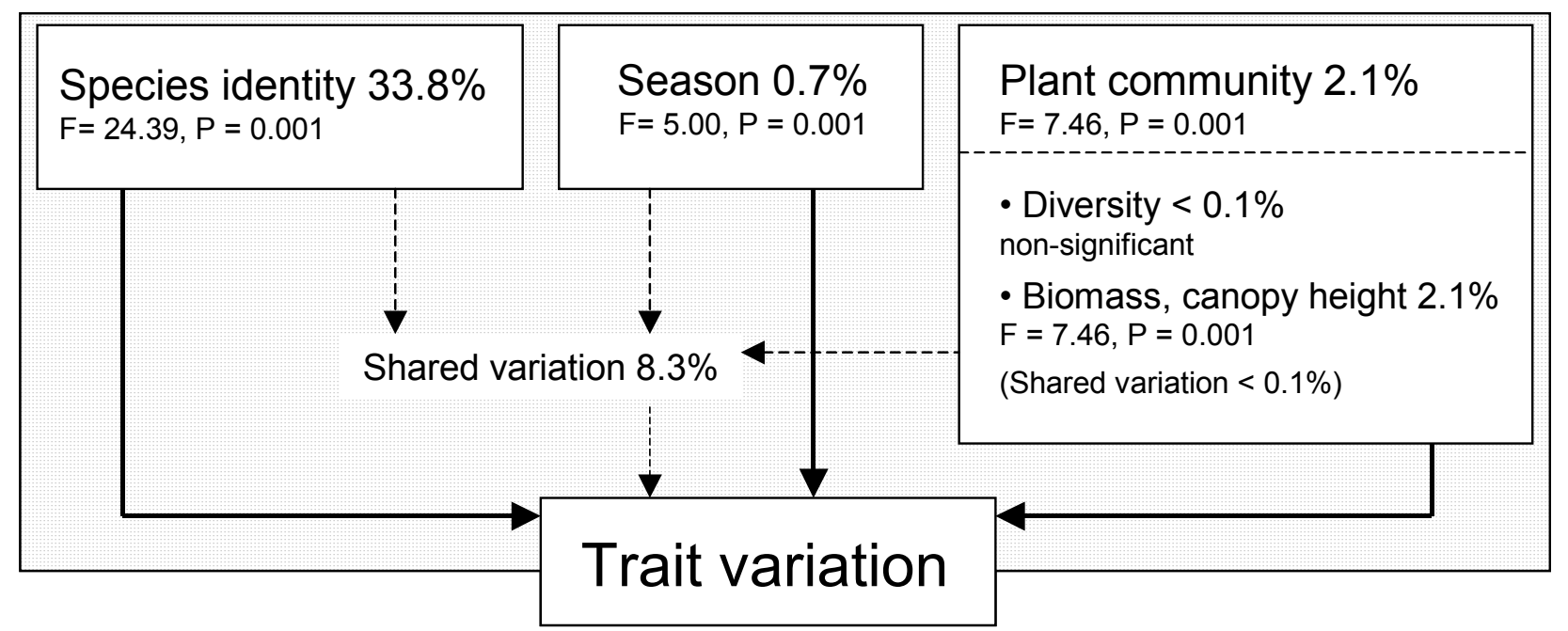

Unexplained variation $42.8 \%$ 
Roscher et al.

Table 1: Number of plots in which the investigated legumes occurred in the experiment. The number of plots in which the original seed mixtures contained the respective legume species is given in parentheses. Abbreviations for life cycle are: $\mathrm{a}=$ annual, ao $=$ annual overwintering, $\mathrm{p}=$ perennial

\begin{tabular}{llllllll}
\hline Species & Life cycle & \multicolumn{2}{l}{ Species richness } \\
& & 1 & 2 & 4 & 8 & 16 & 60 \\
\hline Lathyrus pratensis L. & $\mathrm{p}$ & $2(2)$ & $0(0)$ & $1(1)$ & $2(2)$ & $4(4)$ & $3(3)$ \\
Lotus corniculatus L. & $\mathrm{p}$ & $2(2)$ & $1(1)$ & $1(1)$ & $4(4)$ & $4(4)$ & $3(3)$ \\
Medicago lupulina L. & $\mathrm{ao}, \mathrm{p}$ & $2(2)$ & $2(2)$ & $3(3)$ & $3(4)$ & $2(2)$ & $0(3)$ \\
Medicago x varia Martyn & $\mathrm{p}$ & $2(2)$ & $1(1)$ & $2(2)$ & $1(1)$ & $3(3)$ & $3(3)$ \\
Onobrychis viciifolia Scop. & $\mathrm{p}$ & $2(2)$ & $1(1)$ & $2(2)$ & $4(4)$ & $5(5)$ & $3(3)$ \\
Trifolium campestre Schreb. & $\mathrm{a}$, ao & $2(2)$ & $1(1)$ & $1(1)$ & $2(4)$ & $1(5)$ & $0(3)$ \\
Trifolium dubium Sibth. & $\mathrm{a}$, ao & $2(2)$ & $1(1)$ & $0(0)$ & $2(3)$ & $1(3)$ & $0(3)$ \\
Trifolium fragiferum $\mathrm{L}$. & $\mathrm{p}$ & $1(2)$ & $0(0)$ & $1(1)$ & $1(4)$ & $0(3)$ & $0(3)$ \\
Trifolium hybridum $\mathrm{L}$. & $\mathrm{p}$ & $2(2)$ & $0(0)$ & $1(1)$ & $4(4)$ & $5(5)$ & $3(3)$ \\
Trifolium pratense $\mathrm{L}$. & $\mathrm{p}$ & $2(2)$ & $1(1)$ & $1(1)$ & $1(1)$ & $2(2)$ & $3(3)$ \\
Trifolium repens $\mathrm{L}$. & $\mathrm{p}$ & $2(2)$ & $0(0)$ & $1(1)$ & $0(0)$ & $6(6)$ & $3(3)$ \\
Vicia cracca L. & $\mathrm{p}$ & $2(2)$ & $0(0)$ & $2(2)$ & $1(1)$ & $6(6)$ & $3(3)$ \\
\hline
\end{tabular}




\section{Roscher et al.}

Table 2: Overview of traits investigated on aboveground plant organs in this study

\begin{tabular}{lll}
\hline Variable & Unit & Description \\
\hline Relative module height & $\mathrm{cm} \mathrm{cm}^{-1}$ & Module height divided by canopy height of the surrounding vegetation \\
Module biomass & $\mathrm{mg}$ & Aboveground dry mass per module \\
Leaf : stem ratio & $\mathrm{mg}_{\text {leaf }} \mathrm{mg}^{-1}$ stem & Leaf dry mass per dry mass of supporting tissue \\
Shoot length & $\mathrm{cm}$ & Stretched module length \\
Specific leaf area (SLA) & $\mathrm{mm}^{2}{ }_{\text {leaf }} \mathrm{mg}^{-1}$ leaf & Leaf area per leaf dry mass \\
Leaf nitrogen & $\mathrm{mg} \mathrm{N} \mathrm{g}^{-1}$ leaf & Foliar nitrogen concentration (Nitrogen mass per leaf dry mass) \\
Biomass: $\mathrm{N}$ ratio & $\mathrm{g}_{\mathrm{dw}}\left(\mathrm{g} \mathrm{N}^{-1}\right.$ & Module biomass per unit nitrogen \\
Foliar $\delta^{15} \mathrm{~N}$ & $\%$ & ${ }^{15} \mathrm{~N}$ isotopic signature of leaves \\
Foliar $\delta^{13} \mathrm{C}$ & $\%$ & ${ }^{13} \mathrm{C}$ isotopic signature of leaves \\
Module number & Number of modules per plant individual \\
No. secondary axes & & Number of secondary and higher order lateral axes per module \\
Internode length & Length of the longest internode per module \\
No. inflorescences & $\mathrm{cm}$ & Number of inflorescences per module \\
Phenology & & Phenology of flower and fruit development (ordinal scale)
\end{tabular}


Table 3: Summary of mixed-effects model analyses of functional traits combining all legume species

\begin{tabular}{|c|c|c|c|c|c|c|c|c|c|c|}
\hline \multirow{3}{*}{$\begin{array}{l}\text { Model } \\
\mathrm{R}^{2} \text { statistics }\end{array}$} & \multicolumn{2}{|c|}{ Relative height } & \multicolumn{2}{|l|}{ Module mass } & \multicolumn{2}{|c|}{ Leaf:stem ratio } & \multicolumn{2}{|l|}{ Shoot length } & \multicolumn{2}{|c|}{ Specific leaf area } \\
\hline & A & B & A & B & A & B & A & B & A & B \\
\hline & 0.70 & 0.89 & 0.87 & 0.89 & 0.52 & 0.56 & 0.88 & 0.91 & 0.84 & 0.89 \\
\hline Canopy & -- & $141.62^{* * \star} \downarrow$ & -- & $36.78^{* * *} \uparrow$ & -- & $16.61^{* * \star} \downarrow$ & -- & $133.03^{* * * \uparrow}$ & -- & $53.04 * * * \uparrow$ \\
\hline Biomass & -- & $5.52^{*} \downarrow$ & -- & $4.63^{*} \uparrow$ & -- & 1.68 & -- & $16.85^{* * *} \uparrow$ & -- & 0.84 \\
\hline Mo & $15.29^{* \star \star} \downarrow$ & 0.26 & 0.60 & 0.08 & 0.34 & 1.53 & $10.21^{* \star} \uparrow$ & 0.60 & $4.23^{*} \uparrow$ & 0.19 \\
\hline ID & $104.89 * * *$ & $156.21^{* * *}$ & $345.03^{* * *}$ & $325.99 * * *$ & $64.09^{* * *}$ & 65.78 *** & $237.31 * * *$ & $234.52^{* * *}$ & $230.27^{* * *}$ & $266.33^{* * *}$ \\
\hline ID x Canopy & -- & 40.23 *** & -- & 16.04 . & -- & $23.92^{* *}$ & -- & 15.43 & -- & $42.36^{* * *}$ \\
\hline ID x Biomass & -- & 8.38 & -- & 15.97 & -- & 12.53 & -- & 8.24 & -- & $31.49^{* * *}$ \\
\hline ID $\times$ Mo & $34.91^{* * *}$ & 17.11 & $33.01^{* * *}$ & $26.68^{* *}$ & 4.30 & 1.74 & $61.24^{* * *}$ & $27.45^{* *}$ & $29.22^{\text {** }}$ & 5.87 \\
\hline$I D \times S R$ & 5.00 & 11.44 & $26.00^{* *}$ & $34.90^{* * *}$ & 3.08 & 5.83 & $36.37^{\text {***}}$ & $45.36^{* * *}$ & 40.69 *** & 41.39 *** \\
\hline Season $x$ Biomass & -- & 0.12 & -- & 0.40 & -- & 1.31 & -- & 0.34 & -- & 0.62 \\
\hline Season $\mathrm{x}$ Mo & 2.36 & 0.02 & 0.01 & $4.12 *$ & 0.11 & 1.05 & 0.70 & 6.08 * & 3.16 . & 0.25 \\
\hline Season $x$ SR & 1.95 & $4.37^{*}$ & 0.31 & 0.32 & 0.84 & 0.06 & 0.06 & 1.17 & 0.96 & 2.04 \\
\hline Season $\times$ FG & $26.25^{* * *}$ & 0.76 & 3.30 & 3.68 . & 0.04 & 0.03 & 3.02 . & 1.53 & 1.36 & 0.43 \\
\hline Season $\times$ ID & $36.91^{* * *}$ & $65.49^{* * *}$ & $43.28^{* * *}$ & $34.38^{* * *}$ & $81.73^{* * *}$ & $52.95^{\star * *}$ & $51.23^{* * *}$ & $58.74^{* \star *}$ & $91.24^{* * *}$ & $82.37^{* * *}$ \\
\hline
\end{tabular}

\begin{tabular}{|c|c|c|c|c|c|c|c|c|}
\hline \multirow{4}{*}{$\begin{array}{l}\text { Model } \\
R^{2} \text { statistics }\end{array}$} & \multicolumn{2}{|c|}{ Mass-based leaf $\mathrm{N}$} & \multicolumn{2}{|l|}{ Foliar $\delta^{15} \mathrm{~N}$} & \multicolumn{2}{|l|}{ Foliar $\delta^{13} \mathrm{C}$} & \multicolumn{2}{|c|}{ Biomass: $\mathrm{N}$ ratio } \\
\hline & A & B & A & B & $A$ & B & $A$ & B \\
\hline & 0.73 & 0.76 & 0.61 & 0.66 & 0.65 & 0.75 & 0.80 & 0.82 \\
\hline & $L$ ratio $p$ & $L$ ratio $p$ & $L$ ratio $p$ & $L$ ratio $p$ & $L$ ratio $p$ & $L$ ratio $p$ & $L$ ratio $p$ & $L$ ratio $p$ \\
\hline Canopy & -- & 4.61 & -- & $19.00^{* * *} \downarrow$ & -- & $83.70^{* * \star} \downarrow$ & -- & $45.51^{* * * \uparrow}$ \\
\hline Biomass & -- & 0.05 & -- & $5.76^{*} \downarrow$ & -- & 0.07 & -- & $5.01 * \uparrow$ \\
\hline Mo & 0.66 & 2.51 & $10.88^{* *} \downarrow$ & $6.22^{*} \downarrow$ & $14.60^{* * *} \downarrow$ & $3.17 . \downarrow$ & 0.69 & 1.12 \\
\hline SR & $2.87 . \downarrow$ & 1.52 & $14.44^{* * *} \downarrow$ & $11.04^{* * *} \downarrow$ & 0.20 & 0.90 & 2.26 & 0.32 \\
\hline
\end{tabular}




\begin{tabular}{|c|c|c|c|c|c|c|c|c|}
\hline FG & 0.11 & 0.10 & $9.23^{* *} \downarrow$ & $10.13^{* *} \downarrow$ & 0.04 & 0.20 & 0.01 & 0.08 \\
\hline ID & $171.11^{* * *}$ & $168.60^{* * *}$ & $71.13^{* * *}$ & 67.94 *** & $103.89^{* * *}$ & 117.73 ** & 231.14 *** & $214.81^{* * *}$ \\
\hline ID x Canopy & -- & $46.06^{* * *}$ & -- & 9.53 & -- & 14.05 & -- & $26.95^{* *}$ \\
\hline ID x Biomass & -- & 12.53 & -- & 5.61 & -- & 12.32 & -- & 10.52 \\
\hline ID $\times$ Mo & $25.90^{* *}$ & 14.71 & 22.91 * & $27.14^{* *}$ & $24.79^{* *}$ & $19.57^{*}$ & $35.19^{* * *}$ & $24.66^{* *}$ \\
\hline ID $\times$ SR & 22.96 * & $26.77^{* *}$ & 19.31 * & 23.29 ** & 7.95 & 11.78 & 17.24 & $26.02^{* *}$ \\
\hline ID $\times$ FG & 18.03 & $24.78^{\star \star}$ & 17.04 & 19.30 * & $28.31^{* \star}$ & $37.09^{* \star *}$ & $19.43^{*}$ & $26.01^{* *}$ \\
\hline Season & $16.51^{* \star *} \mathrm{~A}$ & $12.82^{* * *} \mathrm{~A}$ & $26.45^{* * *} \mathrm{~A}$ & $20.64^{* * *} \mathrm{~A}$ & $43.27^{* \star *} \mathrm{~A}$ & 1.90 & 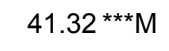 & $14.52^{* * *} \mathrm{M}$ \\
\hline Season $x$ Canopy & -- & $4.23^{*}$ & -- & 2.10 & -- & $17.76^{\star \star \star *}$ & -- & 1.24 \\
\hline Season $\times$ Biomass & -- & 0.12 & -- & 1.55 & -- & 3.40 . & -- & 0.47 \\
\hline Season $\times$ Mo & 0.07 & 0.58 & $4.69 *$ & 0.89 & 0.66 & 0.05 & $<0.01$ & 0.07 \\
\hline Season $\times$ SR & 0.13 & 0.11 & $7.68^{* *}$ & $12.03^{* * *}$ & 0.82 & 0.02 & 0.49 & 0.04 \\
\hline Season x FG & 0.10 & 1.17 & 1.95 & 0.09 & 4.07 * & 0.35 & 1.32 & 0.44 \\
\hline Season x ID & $72.25^{\text {***}}$ & $40.50^{* * *}$ & $34.44^{* * *}$ & $31.95^{\text {***}}$ & $33.78^{* * *}$ & $28.86^{* *}$ & $56.19^{* * *}$ & $30.24^{* * *}$ \\
\hline
\end{tabular}

Models were fitted by stepwise inclusion of variables. Listed are the results of likelihood ratio tests that were applied to assess model improvement (= L ratio), the statistical significance of the explanatory terms, where $. \mathrm{P} \leq 0.10, * \mathrm{P}<0.05, * * \mathrm{P}<0.01$, and $* * * \mathrm{P}<0.001$. $\mathrm{R}^{2}$ statistics is based on likelihood ratio test statistics in comparison to the intercept-only model. The first columns for each trait show models (= model A) where only the experimental factors were fitted. They are followed by columns with models (= model B) where canopy height and community biomass were fitted before the experimental factors. Arrows indicate a significant increase $(\uparrow)$ or decrease $(\downarrow)$ of trait values with increasing community diversity, biomass or canopy height. J (= June) or A (= August) indicate a significant increase or decrease of trait values from the first to the second sampling period, respectively. Abbreviations: ID = species identity, Canopy $=$ canopy height, Biomass $=$ community biomass, $\mathrm{Mo}=$ monoculture vs. mixture contrast, $\mathrm{SR}=$ species number $(\log$-scale $), \mathrm{FG}=$ functional group number, Season $=$ time of sampling (early summer $=$ June, late summer $=$ August $)$. 


\section{Supplementary online material}

Roscher C, Schmid B, Buchmann N, Weigelt A, Schulze E-D. Legume species differ in the responses of their functional traits to plant diversity

Table S1: Summary of mixed-effects model analyses of functional traits combining all legume species

\begin{tabular}{|c|c|c|c|c|c|c|c|c|c|c|}
\hline \multirow{4}{*}{$\begin{array}{l}\text { Model } \\
\mathrm{R}^{2} \text { statistics }\end{array}$} & \multicolumn{2}{|c|}{ Module number } & \multicolumn{2}{|c|}{ No. inflorescences } & \multicolumn{2}{|l|}{ Phenology } & \multicolumn{2}{|c|}{ No. secondary axes } & \multicolumn{2}{|c|}{ Internode length } \\
\hline & $A$ & $\mathrm{~B}$ & $A$ & B & $A$ & B & $A$ & B & $A$ & B \\
\hline & 0.59 & 0.66 & 0.82 & 0.87 & 0.84 & 0.87 & 0.78 & 0.84 & 0.91 & 0.94 \\
\hline & $\mathrm{L}$ ratio $\mathrm{P}$ & $L$ ratio $P$ & L ratio & $\mathrm{L}$ ratio & L ratio $P$ & $L$ ratio $P$ & L ratio $\mathrm{P}$ & L ratio $P$ & L ratio $\mathrm{P}$ & $L$ ratio $P$ \\
\hline Canopy & -- & 1.72 & -- & 2.04 & -- & $27.14^{* * *} \downarrow$ & -- & $51.25^{\star * *} \downarrow$ & -- & $117.65^{* * *} \uparrow$ \\
\hline Biomass & -- & $4.33^{*}$ & -- & 2.61 & -- & $10.34^{* *} \downarrow$ & -- & $9.16^{* *} \downarrow$ & -- & $29.29^{* * *} \uparrow$ \\
\hline Mo & $3.90 * \downarrow$ & $6.28^{*} \downarrow$ & 2.24 & 0.92 & $3.06 . \downarrow$ & 0.66 & 0.37 & 2.20 & $6.11 * \uparrow$ & 1.94 \\
\hline SR & 0.53 & 1.05 & $5.51^{*} \downarrow$ & $5.04 * \downarrow$ & $3.50 . \downarrow$ & 0.44 & $<0.01$ & 1.39 & $6.44^{*} \uparrow$ & 0.68 \\
\hline FG & 0.06 & $<0.01$ & 0.08 & $<0.01$ & 0.02 & 0.01 & 0.99 & 1.54 & 0.42 & 0.09 \\
\hline ID & $79.46^{* * *}$ & $72.50^{* \star *}$ & $184.85^{* \star *}$ & $190.03^{* * *}$ & $180.68^{* * *}$ & $177.89^{* * *}$ & $185.36^{* \star *}$ & $186.34^{* \star *}$ & $240.35^{* * *}$ & $215.43^{* \star *}$ \\
\hline ID x Canopy & -- & 7.11 & -- & 68.29 *** & -- & 15.39 & -- & 16.28 & -- & $105.36^{* * *}$ \\
\hline ID $\times$ Biomass & -- & 1.70 & -- & 19.99 * & -- & 11.04 & -- & 10.14 & -- & 12.42 \\
\hline ID x Mo & 10.69 & 12.05 & $28.18^{* * *}$ & $40.34^{* * *}$ & 16.69 & $37.67^{* * *}$ & 13.09 & $24.27^{* *}$ & $40.92^{* * *}$ & $17.80^{*}$ \\
\hline ID $\times$ SR & 5.72 & 7.75 & 8.76 & $21.39 *$ & 12.47 & $29.48^{* \star \star}$ & $17.44^{*}$ & 15.99 & $19.85^{*}$ & $17.37^{*}$ \\
\hline ID $\times$ FG & 11.54 & $19.74^{* *}$ & 8.51 & $22.80^{* *}$ & 10.09 & 15.59 . & 9.49 & 14.98 & 11.01 & 10.65 \\
\hline Season & $16.90^{* * *} \mathrm{M}$ & $23.74^{* * *} M$ & 3.51 & 0.01 & $63.89^{* * *} \mathrm{~A}$ & $50.67^{* * *} \mathrm{~A}$ & $63.05^{* * *} \mathrm{~A}$ & $4.43{ }^{*} \mathrm{~A}$ & $85.74^{* * *} M$ & $36.42^{* * *} \mathrm{M}$ \\
\hline Season x Canopy & -- & $6.35^{*}$ & -- & $5.00 *$ & -- & $4.88^{*}$ & -- & $14.56^{* * *}$ & -- & 0.59 \\
\hline Season $x$ Biomass & -- & 0.46 & -- & 0.11 & -- & 0.50 & -- & 0.11 & -- & 6.01 * \\
\hline Season $x$ Mo & 0.04 & 2.59 & 3.23 & $<0.01$ & 1.93 & 0.18 & 2.08 & $7.15^{* *}$ & $6.03^{*}$ & $4.53^{*}$ \\
\hline Season $x$ SR & $<0.01$ & 1.29 & 0.38 & $<0.01$ & 0.20 & 0.49 & $5.95^{*}$ & 0.28 & 0.07 & 0.18 \\
\hline Season x FG & 2.57 & 0.12 & 2.21 & 0.18 & 1.22 & 1.61 & 2.27 & 1.10 & 0.36 & 0.67 \\
\hline Season $\times$ ID & $27.71^{* * *}$ & $21.05^{* *}$ & $150.21^{* * *}$ & $82.73^{* * *}$ & $126.32^{* * *}$ & $82.05^{* * *}$ & $49.97^{* * *}$ & $53.91^{* * *}$ & $140.91^{* * *}$ & $55.33^{* * *}$ \\
\hline
\end{tabular}

Models were fitted by stepwise inclusion of variables. Listed are the results of likelihood ratio tests that were applied to assess model improvement (= $\mathrm{L}$ ratio) and the statistical significance of the explanatory terms, where $\mathrm{P} \leq 0.10, * \mathrm{P}<0.05, * * \mathrm{P}<0.01$, and $* * * \mathrm{P}<0.001$. $\mathrm{R}^{2}$ statistics is based on likelihood ratio test statistics in comparison to the intercept-only model. The first columns for each trait shows models (= model A) where only the experimental factors were fitted. They are followed by columns with models (= model B) where canopy height and community biomass were fitted before the experimental factors. Arrows indicate a significant increase $(\uparrow)$ or decrease $(\downarrow)$ of trait values with increasing community 
diversity, biomass or canopy height. J (= June) or A (= August) indicate a significant increase or decrease of trait values from the first to the second sampling period, respectively. For abbreviations see Table 3. 
Table S2: Summary of mixed-effects model analyses of functional traits per legume species

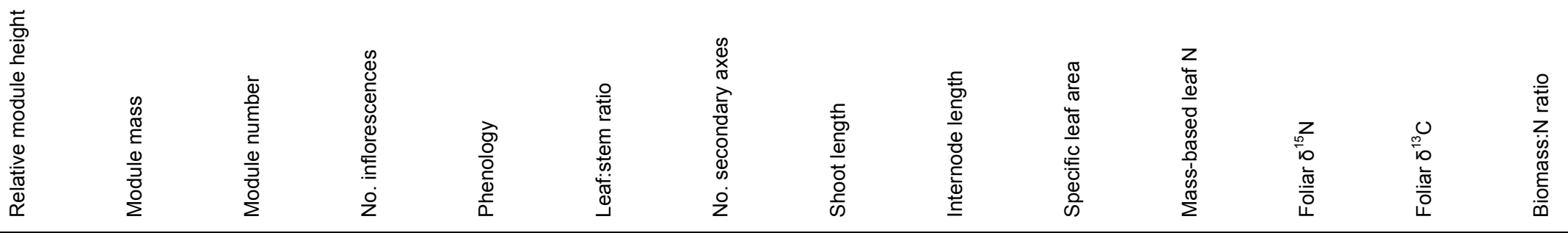

\begin{tabular}{|c|c|c|c|c|c|c|c|c|c|c|c|c|c|c|c|c|c|c|c|c|c|c|c|c|c|c|c|c|}
\hline \multicolumn{29}{|l|}{ Lathyrus pratensis } \\
\hline Model & $A$ & B & A & B & A & B & A & B & A & B & A & B & A & B & A & B & A & $B$ & A & B & A & B & A & B & A & B & A & B \\
\hline $\mathrm{R}^{2}$ statistics & 0.44 & 0.84 & 0.75 & 0.78 & NA & NA & 0.59 & 0.70 & 0.55 & 0.57 & 0.60 & 0.87 & 0.51 & 0.67 & 0.80 & 0.86 & 0.81 & 0.86 & 0.45 & 0.73 & 0.53 & 0.62 & 0.56 & 0.82 & 0.56 & 0.74 & 0.54 & 0.80 \\
\hline Canopy & -- & $\downarrow^{\star * *}$ & -- & $\uparrow^{* *}$ & -- & -- & -- & $\downarrow^{*}$ & -- & ns & -- & $\downarrow^{\star * *}$ & -- & ns & -- & $\uparrow^{\star * *}$ & -- & $\uparrow^{\star * *}$ & -- & ns & -- & ns & -- & ns & -- & $\downarrow^{* *}$ & -- & $\uparrow^{* *}$ \\
\hline Biomass & -- & ns & -- & ns & -- & -- & -- & ns & -- & ns & -- & ns & -- & $\downarrow^{*}$ & -- & ns & -- & $\uparrow$. & -- & $\uparrow$. & -- & ns & -- & ns & -- & ns & -- & $\uparrow^{*}$ \\
\hline Mo & $\downarrow^{*}$ & ns & $\uparrow$. & ns & -- & -- & $\uparrow^{*}$ & ns & ns & ns & $\downarrow^{\star *}$ & ns & ns & $\downarrow$. & $\uparrow^{* *}$ & ns & $\uparrow^{* *}$ & $\mathrm{~ns}$ & ns & ns & ns & $\downarrow^{*}$ & ns & ns & $\downarrow^{*}$ & $\downarrow^{*}$ & ns & $\mathrm{ns}$ \\
\hline SR & ns & . & $\uparrow$. & ns & -- & -- & ns & ns & $\downarrow$. & $\downarrow$. & $\downarrow$. & ns & ns & $\downarrow$. & $\uparrow^{*}$ & ns & $\uparrow$. & ns & $\uparrow^{*}$ & ns & ns & ns & ns & ns & $\downarrow^{*}$ & $\downarrow$. & ns & ns \\
\hline FG & ns & ns & $\uparrow^{* *}$ & $\uparrow^{* *}$ & -- & -- & ns & ns & $\downarrow^{*}$ & $\downarrow^{*}$ & ns & ns & $\downarrow$. & ns & ns & & ns & ns & ns & $\uparrow$. & ns & ns & $\downarrow^{* *}$ & $\downarrow^{* *}$ & $\downarrow^{*}$ & $\downarrow^{*}$ & ns & ns \\
\hline Season & ns & * & ** & * & -- & -- & $* * *$ & ** & ns & ns & ns & ns & * & ns & ** & ns & $* * *$ & * & ns & $* * *$ & *** & *** & . & $* * *$ & ns & ns & ** & ns \\
\hline Season x Canopy & -- & * & -- & ns & -- & -- & -- & ns & -- & ns & -- & ns & -- & ns & -- & ns & -- & ns & -- & ns & -- & . & -- & ns & -- & * & -- & * \\
\hline Season $x$ Biomass & -- & ns & -- & ns & -- & -- & -- & ns & -- & ns & -- & ns & -- & ns & -- & ns & -- & ns & -- & * & -- & ns & -- & ns & -- & ${ }^{\circ}$ & -- & ** \\
\hline Season $\times$ Mo & 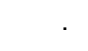 & ns & & * & -- & -- & * & *** & ns & & ** & ** & ns & ns & $* *$ & $* *$ & $* * *$ & *** & 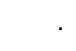 & ns & ns & ns & ns & ** & ns & ns & ns & \\
\hline Season $\times$ SR & ns & ns & ns & ns & -- & -- & ns & ns & . & ns & ns & $* * *$ & ns & ** & ns & & ns & * & ns & ns & ns & ns & ns & * & ns & ns & ns & ns \\
\hline Season x FG & ns & ns & * & * & -- & -- & ns & ns & * & & ns & $\mathrm{ns}$ & & ns & * & ns & ns & ns & ns & ns & ns & ns & ns & ns & ns & ns & ns & ns \\
\hline \multicolumn{29}{|l|}{ Lotus corniculatus } \\
\hline Model & $A$ & B & A & B & A & B & A & B & A & B & A & B & A & B & A & B & A & B & A & B & A & B & A & B & A & B & A & B \\
\hline $\mathrm{R}^{2}$ statistics & 0.77 & 0.94 & 0.46 & 0.54 & 0.53 & 0.68 & 0.30 & 0.34 & 0.38 & 0.39 & 0.63 & 0.77 & 0.58 & 0.69 & 0.68 & 0.79 & 0.82 & 0.88 & 0.62 & 0.71 & 0.65 & 0.73 & 0.66 & 0.72 & 0.47 & 0.72 & 0.72 & 0.87 \\
\hline Canopy & -- & $\downarrow^{\star * *}$ & -- & ns & -- & ns & -- & ns & -- & ns & -- & $\downarrow^{* * *}$ & -- & $\downarrow^{\star * *}$ & -- & $\uparrow^{\star * *}$ & -- & $\uparrow^{* * *}$ & -- & $\uparrow^{* * *}$ & -- & $\downarrow$. & -- & $\downarrow^{*}$ & -- & ns & -- & $\uparrow^{* *}$ \\
\hline Biomass & -- & ns & -- & ns & -- & ns & -- & ns & -- & ns & -- & ns & -- & $\downarrow^{*}$ & -- & ns & -- & $\uparrow^{*}$ & -- & ns & -- & ns & -- & $\downarrow$. & -- & ns & -- & ns \\
\hline Mo & $\downarrow^{* *}$ & ns & ns & ns & $\downarrow^{*}$ & $\downarrow^{*}$ & ns & ns & $\downarrow^{*}$ & ns & $\downarrow^{*}$ & ns & ns & $\downarrow^{* *}$ & $\uparrow^{* *}$ & ns & $\uparrow^{* *}$ & $\uparrow$. & $\uparrow^{*}$ & ns & ns & $\downarrow$. & ns & ns & $\downarrow$. & ns & ns & $\uparrow^{* *}$ \\
\hline SR & $\downarrow^{*}$ & ns & ns & $\downarrow$. & ns & ns & ns & ns & $\downarrow^{*}$ & $\downarrow^{*}$ & ns & ns & ns & ns & ns & ns & $\uparrow$. & ns & $\uparrow^{*}$ & ns & $\downarrow^{* *}$ & $\downarrow$. & $\downarrow^{* *}$ & $\downarrow^{* *}$ & ns & ns & $\uparrow^{*}$ & ns \\
\hline FG & ns & ns & ns & ns & $\downarrow$. & $\downarrow^{*}$ & ns & ns & ns & ns & ns & ns & ns & ns & $\uparrow$. & . & ns & ns & ns & ns & ns & ns & $\downarrow^{* *}$ & $\downarrow^{*}$ & $\downarrow^{*}$ & $\downarrow^{*}$ & $\uparrow^{*}$ & ns \\
\hline Season & $* * *$ & ns & * & . & ns & ns & ns & ns & ns & ns & $* * *$ & ns & $* * *$ & ns & $* * *$ & ns & $* * *$ & $* * *$ & $* * *$ & ns & * & * & * & . & ns & . & $* * *$ & * \\
\hline Season x Canopy & -- & $* * *$ & -- & ns & -- & $* * *$ & -- & ns & -- & ns & -- & ** & -- & ns & -- & * & -- & ns & -- & ns & -- & ** & -- & * & -- & ns & -- & *** \\
\hline
\end{tabular}




\begin{tabular}{|c|c|c|c|c|c|c|c|c|c|c|c|c|c|c|c|c|c|c|c|c|c|c|c|c|c|c|c|c|}
\hline Season $\times$ Biomass & -- & ns & -- & ns & -- & ns & -- & ns & -- & ns & -- & ns & -- & ns & - & ns & -- & ns & -- & ns & -- & ns & -- & ns & -- & ns & -- & 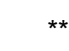 \\
\hline Season $\times$ Mo & ns & ns & * & * & ** & ns & ns & ns & ns & ns & ns & ns & $* *$ & ns & ns & ns & ** & * & ns & ns & ** & ns & ns & $\mathrm{ns}$ & & * & & \\
\hline Season $\times$ SR & . & 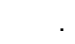 & ns & ns & ns & * & ns & ns & ns & ns & ns & ns & ns & ns & ns & & ns & ns & ns & ns & ns & ns & ns & * & ns & ns & ns & ns \\
\hline Season x FG & * & ns & * & ** & & ns & ns & ns & ns & ns & ns & ns & ns & & & ns & ns & ns & ns & * & ** & *** & * & ns & ns & *** & * & Is \\
\hline \multicolumn{29}{|l|}{ Medicago Iupulina } \\
\hline Model & A & B & A & B & A & B & A & B & A & B & A & B & A & B & A & B & A & B & A & B & A & B & A & B & A & B & A & B \\
\hline $\mathrm{R}^{2}$ statistics & 0.45 & 0.89 & 0.52 & 0.79 & 0.66 & 0.82 & 0.34 & 0.63 & 0.65 & 0.73 & 0.37 & 0.67 & 0.51 & 0.74 & 0.69 & 0.79 & 0.82 & 0.87 & 0.59 & 0.89 & 0.19 & 0.28 & 0.42 & 0.57 & 0.45 & 0.82 & 0.43 & 0.61 \\
\hline Canopy & -- & $\downarrow^{* * *}$ & -- & ns & -- & $\downarrow$. & -- & $\downarrow^{*}$ & -- & $\downarrow^{* *}$ & -- & ns & -- & $\downarrow$. & -- & $\uparrow$. & -- & $\uparrow^{*}$ & -- & $\uparrow^{* * *}$ & -- & ns & -- & ns & -- & $\downarrow^{* * *}$ & -- & ns \\
\hline Biomass & -- & ns & -- & ns & -- & ns & -- & $\downarrow^{*}$ & -- & $\downarrow^{*}$ & -- & ns & -- & ns & -- & ns & -- & ns & -- & $\uparrow^{* * *}$ & -- & ns & -- & ns & -- & ns & -- & ns \\
\hline Mo & $\downarrow^{*}$ & ns & ns & ns & $\downarrow^{*}$ & $\downarrow^{*}$ & ns & ns & ns & $\downarrow^{* *}$ & ns & ns & ns & ns & $\uparrow$. & ns & $\uparrow^{* *}$ & ns & $\uparrow^{*}$ & ns & ns & ns & ns & ns & $\downarrow^{*}$ & $\downarrow$. & ns & ns \\
\hline SR & ns & ns & $\uparrow$. & $\uparrow^{*}$ & ns & ns & ns & ns & ns & ns & ns & ns & ns & $\downarrow$. & $\uparrow^{* *}$ & $\uparrow^{* *}$ & $\uparrow^{* * *}$ & $\uparrow^{* *}$ & ns & ns & ns & ns & $\downarrow$. & $\downarrow$. & ns & ns & ${ }^{*} \uparrow$ & $\uparrow^{*}$ \\
\hline FG & ns & $\downarrow^{*}$ & ns & ns & ns & ns & ns & $\downarrow$. & ns & ns & ns & ns & ns & ns & ns & ns & ns & ns & ns & ns & ns & ns & $\downarrow^{*}$ & $\downarrow^{*}$ & ns & ns & ns & ns \\
\hline Season & ns & * & ** & $* * *$ & $* * *$ & $* * *$ & ns & ns & *** & * & $* * *$ & $* * *$ & $* * *$ & $* * *$ & $* * *$ & $* * *$ & $* * *$ & $* * *$ & ** & ns & ns & ns & . & * & ns & ** & ns & * \\
\hline Season x Canopy & -- & ns & -- & ns & -- & * & -- & ns & -- & ns & -- & ns & -- & ns & -- & ns & -- & ns & -- & ns & -- & ns & -- & ns & -- & ns & -- & ns \\
\hline Season x Biomass & -- & ** & -- & ns & -- & ns & -- & * & -- & & -- & * & -- & * & -- & ns & -- & ns & -- & ns & -- & ns & -- & ns & -- & ns & -- & ns \\
\hline Season x Mo & . & ns & ns & ns & ns & ns & * & ns & * & ns & ns & ns & ns & ns & ns & ns & ns & ns & ns & ns & ns & ns & ns & ns & ns & ns & . & ns \\
\hline Season $\times$ SR & ns & * & ns & ** & ns & ** & ns & ns & ns & ns & ns & * & ns & & . & ** & ns & ns & ns & ns & ns & ns & ns & ns & ns & * & ns & * \\
\hline Season x FG & & ns & ns & ns & ns & ns & ns & ns & ns & ns & ns & ns & ns & ns & ns & ns & ns & ns & * & ** & ns & ns & ns & & * & $\mathrm{ns}$ & ns & $\mathrm{ns}$ \\
\hline \multicolumn{29}{|l|}{ Medicago x varia } \\
\hline Model & A & B & A & B & A & B & A & B & A & B & A & B & A & B & A & B & A & B & A & B & A & B & A & B & A & B & A & B \\
\hline $\mathrm{R}^{2}$ statistics & 0.80 & 0.90 & 0.34 & 0.45 & 0.60 & 0.67 & 0.80 & 0.85 & 0.78 & 0.91 & 0.67 & 0.82 & 0.83 & 0.86 & 0.59 & 0.80 & 0.71 & 0.83 & 0.65 & 0.88 & 0.25 & 0.66 & 0.52 & 0.58 & 0.19 & 0.84 & 0.31 & 0.49 \\
\hline Canopy & -- & $\downarrow^{\star * *}$ & -- & $\downarrow^{*}$ & -- & ns & -- & ns & -- & ns & -- & $\downarrow^{\star * *}$ & -- & $\downarrow$. & -- & $\uparrow^{* * *}$ & -- & $\uparrow^{* * *}$ & -- & $\uparrow^{* *}$ & -- & ns & -- & ns & -- & $\downarrow^{*}$ & -- & $\mathrm{ns}$ \\
\hline Biomass & -- & ns & -- & ns & -- & ns & -- & ns & -- & ns & -- & ns & -- & ns & -- & ns & -- & ns & -- & ns & -- & ns & -- & ns & -- & ns & -- & ns \\
\hline Mo & $\downarrow^{* *}$ & ns & ns & $\downarrow^{*}$ & ns & ns & ns & $\downarrow^{*}$ & ns & ns & ns & ns & ns & $\downarrow^{* *}$ & $\uparrow^{* *}$ & ns & ns & $\uparrow^{* * *}$ & $\uparrow$. & ns & ns & ns & ns & ns & ns & ns & ns & ns \\
\hline SR & ns & $\downarrow^{* *}$ & ns & ns & $\downarrow^{* *}$ & $\downarrow^{* * *}$ & ns & $\downarrow$. & ns & $\downarrow$. & $\downarrow^{* *}$ & * & ns & ns & ns & ns & $\uparrow^{*}$ & ns & ns & $\uparrow^{* * *}$ & ns & ns & $\downarrow^{* * *}$ & $\downarrow^{* * *}$ & ns & ns & $\uparrow^{*}$ & $\uparrow^{*}$ \\
\hline FG & ns & ns & ns & ns & $\downarrow$. & ns & $\downarrow^{*}$ & $\downarrow^{* * *}$ & $\downarrow$. & $\downarrow^{*}$ & ns & ns & ns & $\downarrow^{* *}$ & ns & ns & ns & ** & $\uparrow^{* *}$ & $\uparrow^{*}$ & ns & ns & ns & ns & ns & ns & ns & רs \\
\hline Season & $* * *$ & ** & ** & . & * & . & $* * *$ & $* * *$ & $* * *$ & $* * *$ & ** & ns & $* * *$ & $* * *$ & * & ns & $* * *$ & ns & $* * *$ & ns & ns & ns & . & . & ns & ns & ns & ns \\
\hline Season $x$ Canopy & -- & ns & -- & ns & -- & ns & -- & . & -- & *** & -- & ** & -- & ns & -- & * & -- & . & -- & ns & -- & ns & -- & ns & -- & ns & -- & ns \\
\hline Season x Biomass & -- & ns & -- & ns & -- & ns & -- & . & -- & ns & -- & ns & -- & ns & -- & ns & -- & ns & -- & $* * *$ & -- & * & -- & ns & -- & ns & -- & $\mathrm{ns}$ \\
\hline Season x Mo & ns & ns & ns & ns & ns & ns & ns & ns & ns & & ns & ** & ns & ns & . & ** & * & ns & ns & ns & ns & ** & ns & ns & ns & $* * *$ & ns & . \\
\hline Season $\times \mathrm{SR}$ & * & ns & ns & ns & . & ns & ns & * & ns & ns & ns & ns & ns & * & ns & . & ns & ns & ns & ns & ns & . & ns & ns & ns & *** & ns & is \\
\hline Season $\times$ FG & ns & ns & ns & ns & ns & & ** & ns & & ns & & ns & * & & ns & ns & ns & * & ns & $\mathrm{ns}$ & ns & & ns & ns & ns & $\mathrm{ns}$ & ns & $\underline{s}$ \\
\hline
\end{tabular}


Model

$\mathrm{R}^{2}$ statistics

Canopy

$\begin{array}{lllllllllllllllllllllllllllllllllllllllllllllllll}\text { A } & \text { B } & \text { A } & \text { B } & \text { A } & \text { B } & \text { A } & \text { B } & \text { A } & \text { B } & \text { A } & \text { B } & \text { A } & \text { B } & \text { A } & \text { B } & \text { A } & \text { B } & \text { A } & \text { B } & \text { A } & \text { B } & \text { A } & \text { B } & \text { A } & \text { B } & \text { A } & \text { B }\end{array}$

Biomass

Mo

SR

FG

Season

Season $x$ Canopy

Season $x$ Biomass

Season $x$ Mo

Season $\times S R$

Season $x$ FG

Trifolium campestre

Model

$\mathrm{R}^{2}$ statistics

Canopy

Biomass

Mo

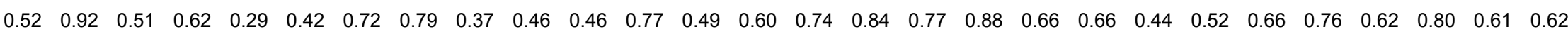

FG

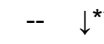

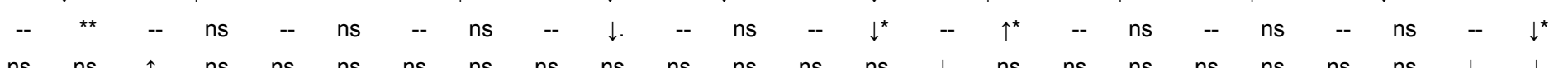

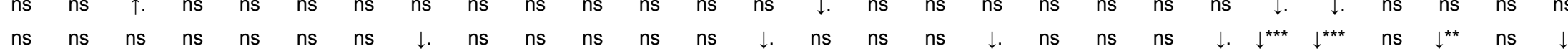

ns ns ns ns ns ns $\downarrow^{*} \quad \downarrow$. ns ns ns ns ns ns ns ns ns ns ns ns ns ns $\quad$ ns ns ns ns ns ns

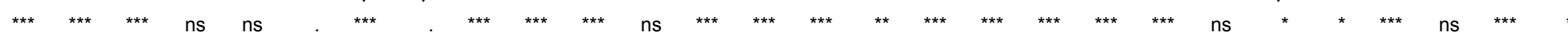

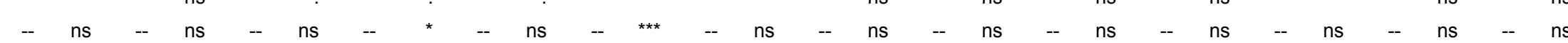

ns ns ns ns ns * ns ns ns ns ns ns ns ns ns ns ns ns ns ns ns ns * ns * ns ns ns

ns ns ns ns ns ns ns ns ns ns ns ns ns ns ns ns ns ns ns ns ns ns ** ** ns ns ns ns ${ }^{* * *}$ ns. $n s$. ns ${ }^{* *}$ ns $n s \quad n s \quad n s \quad n s \quad n s \quad n s \quad n s \quad n s \quad n s \quad n s \quad n s \quad n s \quad n s \quad n s \quad n s \quad n s \quad n s$. ns ns

Trifolium dubium

Model

$\mathrm{R}^{2}$ statistics

$\begin{array}{lllllllllllllllllllllllllllllllllllllll}\text { B } & \text { A } & \text { B } & \text { A } & \text { B } & \text { A } & \text { B } & \text { A } & \text { B } & \text { A } & \text { B } & \text { A } & \text { B } & \text { A } & \text { B } & \text { A } & \text { B } & \text { A } & \text { B } & \text { A } & \text { B } & \text { A } & \text { B } & \text { A } & \text { B } & \text { A } & \text { B }\end{array}$

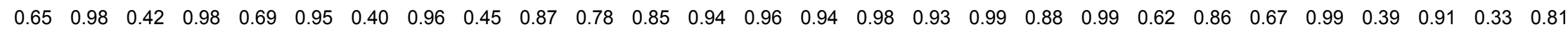

\section{Canopy}

Biomass

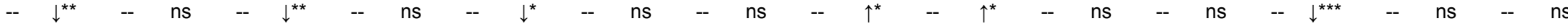

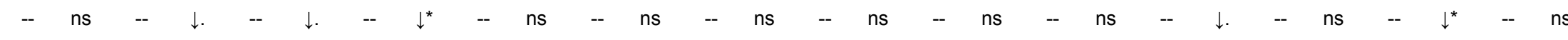

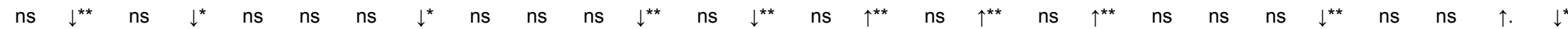

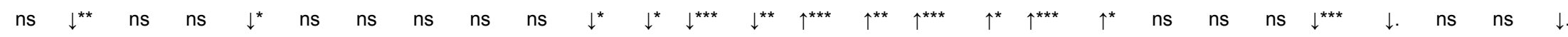
Mo

SR

FG

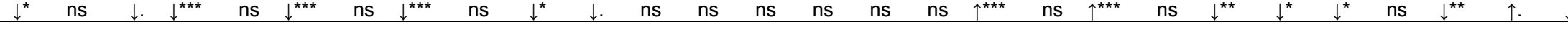

\section{Trifolium hybridum}




\begin{tabular}{|c|c|c|c|c|c|c|c|c|c|c|c|c|c|c|c|c|c|c|c|c|c|c|c|c|c|c|c|c|}
\hline Biomass & -- & ns & -- & ns & -- & ns & -- & $\mathrm{ns}$ & -- & ns & -- & $\mathrm{ns}$ & -- & ns & -- & $\uparrow^{*}$ & -- & ns & -- & ns & -- & ns & -- & ns & -- & ns & -- & ns \\
\hline Mo & $\downarrow^{* * *}$ & ns & ns & ns & $\downarrow$. & ns & ns & ns & ns & ns & ns & ns & ns & ns & $\uparrow^{* *}$ & $\uparrow$. & $\uparrow^{* *}$ & $\uparrow$. & $\uparrow$. & ns & ns & ns & $\downarrow^{* * *}$ & $\downarrow^{* * *}$ & $\downarrow$. & ns & $\uparrow^{* *}$ & $\uparrow^{*}$ \\
\hline SR & $\downarrow$. & ns & $\uparrow^{* *}$ & $\uparrow^{\star *}$ & $\downarrow^{*}$ & $\downarrow^{*}$ & ns & ns & ns & ns & $\downarrow^{*}$ & $\downarrow^{\star *}$ & $\downarrow$. & $\downarrow^{\star *}$ & $\uparrow^{* * *}$ & $\uparrow^{* * *}$ & $\uparrow^{* *}$ & $\uparrow^{* *}$ & ns & ns & ns & ns & ns & ns & ns & ns & $\uparrow^{* * *}$ & $\uparrow^{* *}$ \\
\hline FG & ns & ns & ns & ns & ns & $\downarrow^{*}$ & ns & ns & $\downarrow^{* *}$ & $\downarrow^{\star *}$ & $\downarrow^{\star *}$ & $\downarrow^{*}$ & ns & ns & $\uparrow$. & $\uparrow$. & $\uparrow$. & $\uparrow$. & $\uparrow^{* *}$ & $\uparrow^{\star * *}$ & ns & ns & $\downarrow$. & $\downarrow$. & $\downarrow^{*}$ & $\downarrow^{*}$ & ns & $\uparrow$. \\
\hline Season & $* * *$ & $* *$ & ns & ns & ns & $* * *$ & $* \star \star$ & $\star * *$ & $* * *$ & $\star * *$ & . & * & $* * *$ & ns & $* *$ & . & ** & ns & $* * *$ & ns & ns & ns & ns & * & $* \star *$ & ns & ns & ss \\
\hline Season x Canopy & -- & $* * *$ & -- & . & -- & ** & -- & ns & -- & ns & -- & ns & -- & ns & * & * & -- & ** & -- & . & -- & ns & -- & ns & -- & *** & -- & is \\
\hline Season x Biomass & -- & ns & -- & ns & -- & ns & -- & ns & -- & ns & -- & . & -- & ns & -- & . & -- & ns & -- & ns & -- & ns & -- & ns & -- & ns & -- & IS \\
\hline Season x Mo & ns & ns & ** & ns & ns & ns & ns & ns & ns & ns & ns & ns & ns & ns & $* * *$ & ns & ** & ns & ns & ns & ns & ns & * & ns & ns & ** & ns & רs \\
\hline Season $\times$ SR & * & ns & ns & ns & ** & . & ns & ns & ns & ** & * & . & ns & ns & ns & ns & * & ns & ns & ns & ns & ns & ns & ns & . & ns & ns & רs \\
\hline Season x FG & ** & * & ns & ns & ns & ns & ns & ns & * & & . & . & ns & ns & ns & $\mathrm{ns}$ & ns & ns & ns & ns & ns & ns & ns & ns & & ns & ns & ss \\
\hline \multicolumn{29}{|l|}{ Trifolium pratense } \\
\hline Model & A & B & A & B & A & B & A & B & A & B & A & B & A & B & $A$ & B & A & B & A & B & A & B & A & B & A & B & A & P \\
\hline $\mathrm{R}^{2}$ statistics & 0.85 & 0.97 & 0.52 & 0.72 & 0.38 & 0.46 & 0.59 & 0.70 & 0.88 & 0.89 & 0.61 & 0.83 & 0.68 & 0.76 & 0.79 & 0.92 & 0.79 & 0.84 & 0.87 & 0.99 & 0.49 & 0.80 & 0.84 & 0.97 & 0.69 & 0.74 & 0.62 & 0.87 \\
\hline Canopy & -- & $\downarrow^{\star \star *}$ & -- & ns & -- & ns & -- & ns & -- & ns & -- & ns & -- & ns & -- & $\uparrow^{* * *}$ & -- & $\uparrow^{* *}$ & -- & $\uparrow^{* * *}$ & -- & $\downarrow^{*}$ & -- & $\downarrow$. & -- & $\downarrow^{* * *}$ & -- & ss \\
\hline Biomass & -- & ns & -- & $\downarrow$. & -- & ns & -- & $\downarrow$. & -- & $\downarrow^{*}$ & -- & $\downarrow^{*}$ & -- & ns & -- & $\uparrow^{* *}$ & -- & $\uparrow^{* *}$ & -- & ns & -- & ns & -- & ns & -- & $\downarrow^{*}$ & -- & ns \\
\hline Mo & $\downarrow^{\star *}$ & ns & $\uparrow^{*}$ & $\uparrow^{*}$ & ns & $\downarrow^{*}$ & $\uparrow$. & $\uparrow^{*}$ & ns & $\downarrow^{*}$ & ns & $\downarrow^{*}$ & ns & $\uparrow^{* *}$ & $\uparrow^{\star *}$ & $\uparrow^{* *}$ & $\uparrow^{* *}$ & $\uparrow^{*}$ & $\uparrow^{*}$ & ns & ns & ns & ns & ns & $\downarrow^{*}$ & ns & $\uparrow^{* *}$ & $\uparrow^{\star *}$ \\
\hline SR & $\downarrow^{* *}$ & ns & ns & ns & ns & ns & ns & ns & ns & $\downarrow$. & $\downarrow^{*}$ & $\downarrow^{* * *}$ & ns & ns & $\uparrow^{*}$ & $\uparrow^{*}$ & $\uparrow^{*}$ & $\uparrow$. & ns & ns & $\downarrow^{*}$ & $\downarrow^{*}$ & $\downarrow^{\star *}$ & $\downarrow^{*}$ & $\downarrow$. & ns & ns & ns \\
\hline FG & ns & $\downarrow^{*}$ & $\downarrow$. & $\downarrow^{*}$ & ns & ns & ns & ns & ns & ns & $\downarrow^{*}$ & $\downarrow$. & ns & ns & $\uparrow^{* *}$ & $\uparrow^{\star *}$ & $\uparrow^{* * *}$ & $\uparrow$. & $\uparrow^{*}$ & ns & ns & ns & $\downarrow^{\star * *}$ & $\downarrow^{* * *}$ & ns & ns & $\uparrow^{*}$ & $\uparrow^{* *}$ \\
\hline Season & ** & * & ns & ns & * & . & ** & * & $* * *$ & *** & . & ns & * & * & $* *$ & * & ns & . & $* * *$ & * & ns & ns & ns & $\downarrow^{*}$ & $* * *$ & & ns & ns \\
\hline Season x Canopy & -- & ** & -- & ns & -- & ns & -- & * & -- & $* *$ & -- & ns & -- & ** & -- & ns & -- & ns & -- & . & -- & ns & -- & ** & -- & ns & -- & רs \\
\hline Season x Biomass & -- & ns & -- & ns & -- & ns & -- & . & -- & ns & -- & . & -- & ns & -- & ns & -- & . & -- & *** & -- & . & -- & ns & -- & ns & -- & ns \\
\hline Season x Mo & ns & ns & ns & ns & ns & ns & ns & ns & ** & ns & ns & $* * *$ & ns & ns & ns & ns & ns & ns & $* * *$ & ns & ns & & ns & . & ns & ns & ns & ns \\
\hline Season $\times$ SR & ns & $* *$ & ns & ns & ns & ns & ns & ns & . & ns & ns & * & * & ns & ns & ns & ns & ns & ns & ns & ns & ** & * & $* * *$ & ns & ns & ns & *** \\
\hline Season x FG & ** & *** & ns & ns & ns & ns & ns & ns & ns & ns & & ns & ns & * & ns & ns & & ns & ns & ns & * & ** & * & * & ns & ns & ns & * \\
\hline \multicolumn{29}{|l|}{ Trifolium repens } \\
\hline Model & A & B & A & B & A & B & A & B & A & B & A & B & A & B & A & B & A & B & A & B & A & B & A & B & A & B & A & B \\
\hline $\mathrm{R}^{2}$ statistics & 0.72 & 0.96 & 0.62 & 0.99 & 0.69 & 0.86 & NA & NA & 0.34 & 0.57 & 0.92 & 0.95 & NA & NA & 0.77 & 0.85 & NA & NA & 0.54 & 0.63 & 0.63 & 0.71 & 0.77 & 0.84 & 0.57 & 0.91 & 0.55 & 0.62 \\
\hline Canopy & -- & $\downarrow^{* * *}$ & -- & ns & -- & ns & -- & -- & -- & ns & -- & $\downarrow^{* * *}$ & -- & -- & -- & $\uparrow^{* * *}$ & -- & -- & -- & ns & -- & $\downarrow^{* * *}$ & -- & $\downarrow$. & -- & $\downarrow^{\star * *}$ & -- & $\uparrow^{* *}$ \\
\hline Biomass & -- & ns & -- & ns & -- & ns & -- & -- & -- & $\downarrow^{*}$ & -- & $\downarrow^{*}$ & -- & -- & -- & $\uparrow^{* *}$ & -- & -- & -- & ns & -- & $\downarrow^{*}$ & -- & ns & -- & ns & -- & $\uparrow^{*}$ \\
\hline Mo & $\downarrow^{* *}$ & $\downarrow^{* *}$ & ns & $\downarrow^{*}$ & $\downarrow^{*}$ & $\downarrow$. & -- & -- & ns & ns & $\downarrow^{* *}$ & ns & -- & -- & $\uparrow^{* *}$ & ns & -- & -- & ns & ns & $\downarrow^{* *}$ & ns & $\downarrow^{\star * *}$ & $\downarrow^{* * *}$ & $\downarrow^{*}$ & ns & $\uparrow^{*}$ & ns \\
\hline SR & $\downarrow^{* *}$ & $\downarrow^{*}$ & ns & $\downarrow^{*}$ & $\downarrow^{*}$ & $\downarrow^{* *}$ & -- & -- & ns & ns & $\downarrow$. & $\downarrow^{* * *}$ & -- & -- & $\uparrow^{*}$ & ns & -- & -- & ns & ns & $\downarrow^{* *}$ & $\downarrow$. & $\downarrow$. & ns & ns & ns & $\uparrow^{*}$ & ns \\
\hline FG & ns & ns & ns & ns & $\downarrow^{*}$ & $\downarrow^{* *}$ & -- & -- & $\downarrow$. & ns & ns & $\downarrow^{*}$ & -- & -- & ns & ns & -- & -- & $\uparrow$. & ns & ns & $\downarrow$. & ns & ns & $\downarrow^{*}$ & $\downarrow^{*}$ & ns & ** \\
\hline Season & ** & ns & *** & *** & -- & -- & -- & -- & -- & -- & 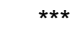 & *** & -- & -- & $\star \star \star *$ & ns & -- & -- & * & ns & * & ns & ns & ns & ns & ** & ** & \\
\hline
\end{tabular}




\begin{tabular}{|c|c|c|c|c|c|c|c|c|c|c|c|c|c|c|c|c|c|c|c|c|c|c|c|c|c|c|c|c|}
\hline Season x Canopy & -- & $* \star *$ & -- & ns & -- & -- & -- & -- & -- & -- & -- & ns & -- & -- & -- & ns & -- & -- & -- & * & -- & ns & -- & ns & -- & *** & -- & $\mathrm{ns}$ \\
\hline Season $x$ Biomass & -- & ns & -- & ns & -- & -- & -- & -- & -- & -- & -- & ns & -- & -- & -- & ns & -- & -- & -- & ns & -- & ns & -- & * & -- & . & -- & is \\
\hline Season $\times$ Mo & ns & ns & ns & ns & -- & -- & -- & -- & -- & -- & * & ns & -- & -- & ns & ns & -- & -- & ns & ns & ns & ns & ns & ns & ns & ns & ns & \\
\hline Season x SR & ns & * & ns & ns & -- & -- & -- & -- & -- & -- & ns & ns & -- & -- & ns & ns & -- & -- & . & ns & ns & ns & ns & ns & ns & ns & ns & is \\
\hline Season $\times$ FG & ns & ns & ns & ns & -- & -- & -- & -- & -- & -- & ** & . & -- & -- & ns & ns & -- & -- & * & * & ns & ns & ns & ns & . & ** & ns & s \\
\hline \multicolumn{29}{|l|}{ Vicia cracca } \\
\hline Model & $A$ & B & A & B & A & B & A & B & A & B & A & B & A & B & A & B & A & B & A & $\mathrm{B}$ & A & B & A & B & A & B & A & B \\
\hline $\mathrm{R}^{2}$ statistics & 0.59 & 0.87 & 0.68 & 0.77 & NA & NA & 0.79 & 0.84 & 0.69 & 0.74 & 0.44 & 0.80 & 0.44 & 0.60 & 0.72 & 0.74 & 0.76 & 0.79 & 0.47 & 0.85 & 0.69 & 0.79 & 0.49 & 0.65 & 0.47 & 0.86 & 0.70 & 0.76 \\
\hline Canopy & -- & $\downarrow^{* * *}$ & -- & $\uparrow$. & -- & -- & -- & ns & -- & ns & -- & $\downarrow^{*}$ & -- & $\downarrow$. & -- & $\uparrow^{* * *}$ & -- & $\uparrow^{* * *}$ & -- & $\uparrow^{* *}$ & -- & ns & -- & $\downarrow^{*}$ & -- & $\downarrow^{* * *}$ & -- & is \\
\hline Biomass & -- & ns & -- & ns & -- & -- & -- & $\downarrow^{*}$ & -- & $\downarrow^{*}$ & -- & $\downarrow$. & -- & $\downarrow^{*}$ & -- & ns & -- & $\uparrow^{*}$ & -- & $\uparrow^{*}$ & -- & ns & -- & $\downarrow^{* *}$ & -- & ns & -- & $\mathrm{ns}$ \\
\hline Mo & ns & ns & $\downarrow^{* *}$ & $\downarrow^{* *}$ & -- & -- & $\downarrow^{* * *}$ & $\downarrow^{* * *}$ & $\downarrow^{* * *}$ & $\downarrow^{* * *}$ & $\downarrow$. & ns & ns & ns & ns & $\uparrow^{*}$ & ns & ns & $\uparrow$. & ns & $\uparrow^{*}$ & $\uparrow$. & $\downarrow^{*}$ & ns & $\downarrow^{*}$ & $\downarrow^{*}$ & $\downarrow^{* *}$ & $\downarrow^{* *}$ \\
\hline SR & $\downarrow^{*}$ & ns & ns & $\downarrow^{*}$ & -- & -- & ns & ns & ns & ns & $\downarrow^{* *}$ & $\downarrow^{* *}$ & ns & ns & ns & ns & $\uparrow^{*}$ & ns & $\uparrow^{* *}$ & $\uparrow^{* *}$ & $\uparrow$. & $\uparrow^{* *}$ & $\downarrow^{* *}$ & $\downarrow^{*}$ & ns & ns & ns & $\downarrow^{* *}$ \\
\hline FG & $\downarrow^{*}$ & ns & $\downarrow$. & . & -- & -- & ns & ns & ns & ns & ns & ns & ns & ns & ns & $\uparrow$. & ns & ns & ns & ns & $\uparrow$. & ns & ns & ns & ns & ns & ns & ns \\
\hline Season & $* *$ & * & $* * *$ & ** & -- & -- & * & ** & ns & * & ns & * & ** & $* *$ & *** & * & $* * *$ & * & ns & $\star * \star$ & $* * *$ & $* \star *$ & ns & ns & ns & $* * *$ & $\star * * *$ & * \\
\hline Season x Canopy & -- & * & -- & * & -- & -- & -- & ns & -- & ns & -- & ns & -- & ns & -- & ns & -- & ns & -- & ns & -- & ns & -- & ns & -- & ns & -- & ns \\
\hline Season x Biomass & -- & ns & -- & ns & -- & -- & -- & ns & -- & ns & -- & ** & -- & ns & -- & ns & -- & ns & -- & * & -- & . & -- & ns & -- & $* * *$ & -- & ns \\
\hline Season $\times$ Mo & ns & ns & ns & * & -- & -- & $* * *$ & ** & * & . & ns & ns & ns & * & ns & ns & ns & ns & ns & ns & ns & $* *$ & ns & * & ns & . & ns & ** \\
\hline Season $\times$ SR & ns & ns & . & ns & -- & -- & ns & ns & ns & ns & ns & * & . & ns & ns & ns & ns & ns & ns & ns & ns & ns & ns & ns & ns & * & * & רs \\
\hline Season $\times$ FG & * & ns & ns & ns & -- & -- & ns & ns & ns & & ns & . & ns & ns & ns & ns & ns & ns & ns & ns & ns & ns & ns & ns & * & * & ns & רs \\
\hline
\end{tabular}

Models were fitted by stepwise inclusion of variables. Listed are the results of likelihood ratio tests that were applied to assess model improvement and the statistical significance of the variables, where $\mathrm{P} \leq 0.10, * \mathrm{P}<0.05, * * \mathrm{P}<0.01$, and $* * * \mathrm{P}<0.001$. $\mathrm{R}^{2}$ statistics is based on likelihood ratio test statistics in comparison to the intercept-only model. The first column for each trait shows models (= model A) where only the experimental factors were fitted, the second column for each trait shows models (= model B) where canopy height and community biomass were fitted before the experimental factors. Note that the number of replicates was too low to include both covariates in models for $T$. dubium. Here, we separately tested each canopy height and community biomass and selected the model with the larger $R^{2}$. Arrows indicate a significant increase ( $\left.\uparrow\right)$ or decrease $(\downarrow)$ of trait values with increasing community diversity, biomass or canopy height. Dashes indicate absence of measurements or terms not fitted in the respective model. For abbreviations see Table 3. 
Figure S1: Foliar $\delta^{15} \mathrm{~N}$ values of (a) Lolium perenne and (b) Taraxacum officinale used as non- $\mathrm{N}_{2}$-fixing reference species with the ${ }^{15} \mathrm{~N}$ natural abundance method plotted against sown species number. All values are plot means of values measured in samples collected in June (before first mowing) and August (before second mowing) 2006. The lines are arithmetic means for values per species-richness level.

(a) Lolium perenne

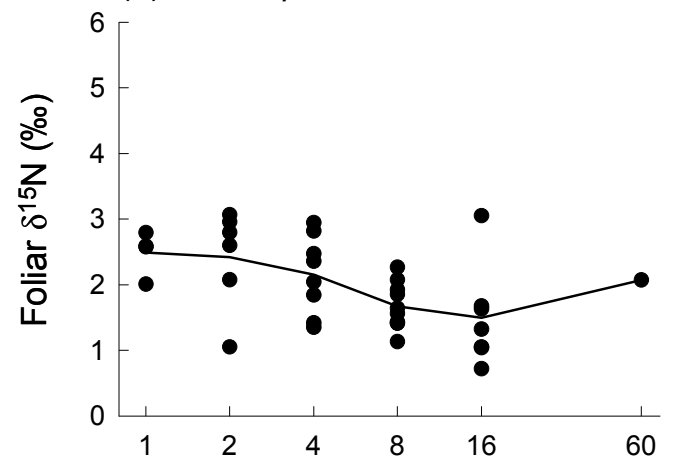

(b) Taraxacum officinale

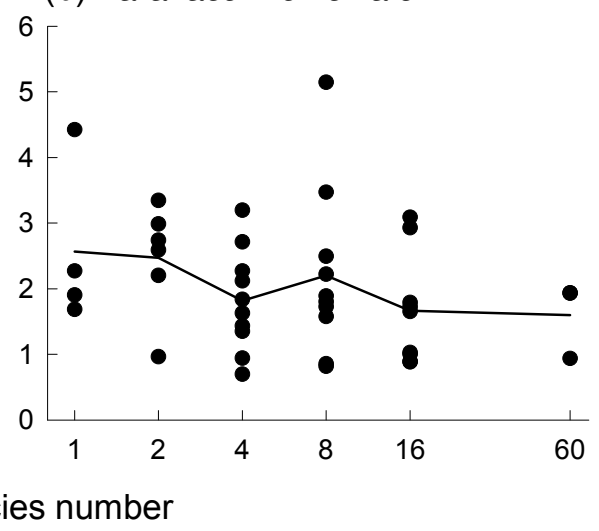


Figure S2: Trait values in mixtures (Mix) plotted against trait values in monocultures (Mono). All values are means of values measured in June (before first mowing) and August (before second mowing). Monoculture values are averaged between two replicated plots per species. Values above the diagonal line indicate cases where trait values in mixtures were larger than in monoculture. For species symbols see Fig. 3.

(a)

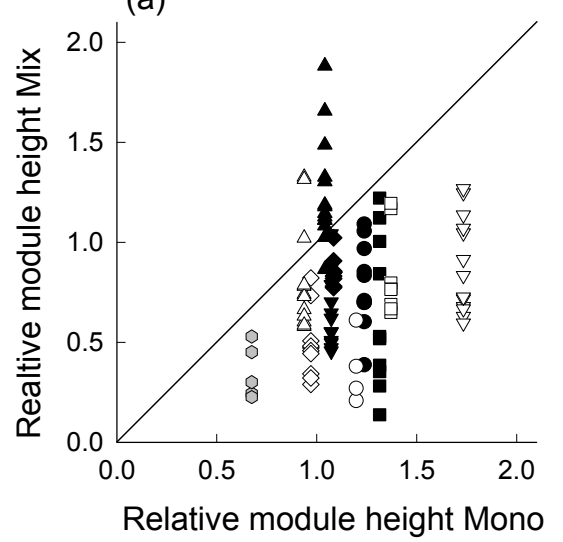

(d)

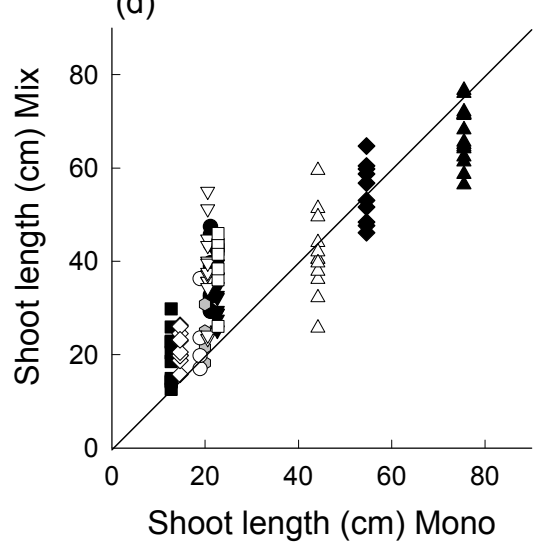

(g)

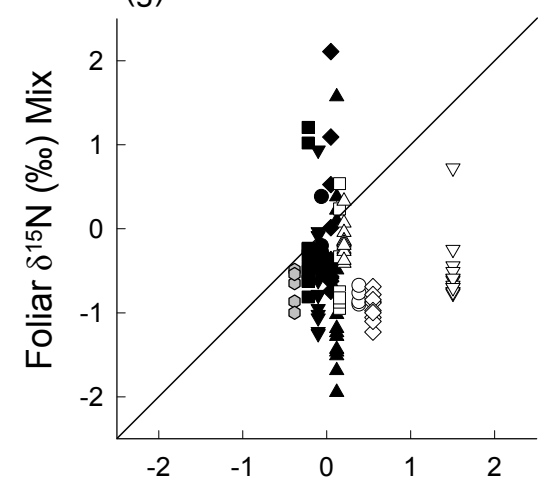

Foliar $\delta^{15} \mathrm{~N}(\%)$ Mono (b)

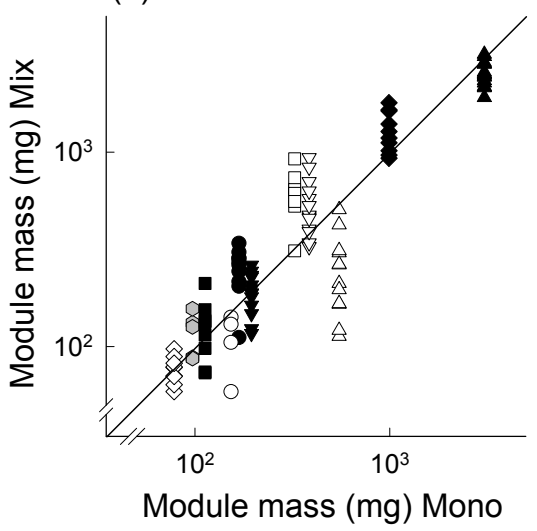

(e)

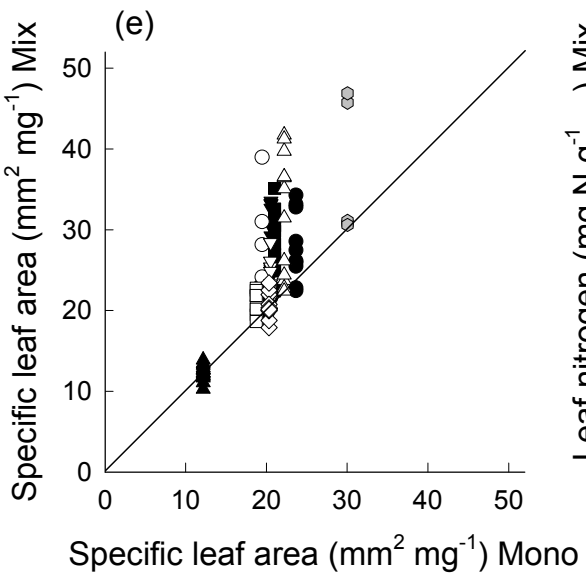

(h)

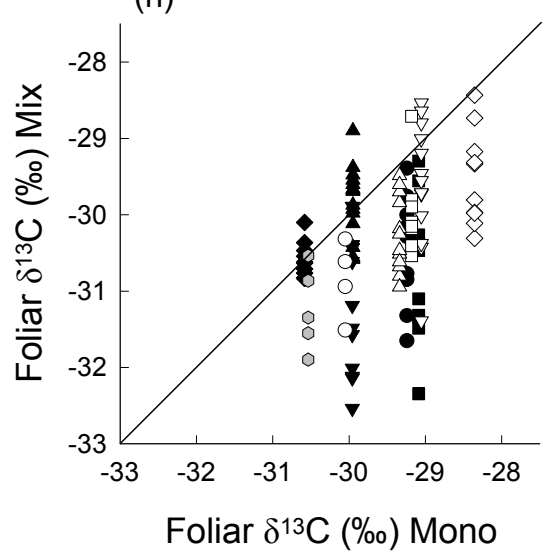

(c)

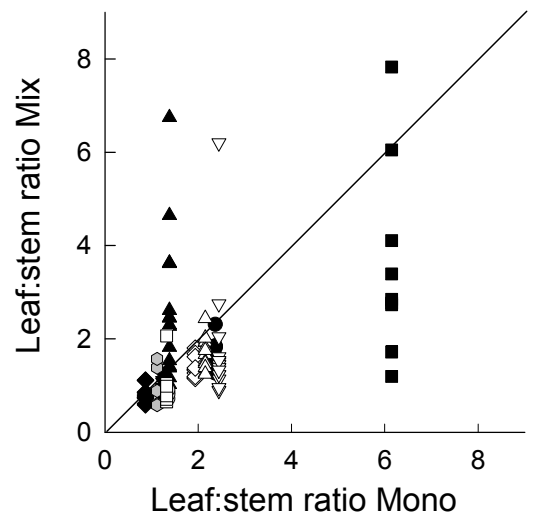

(f)
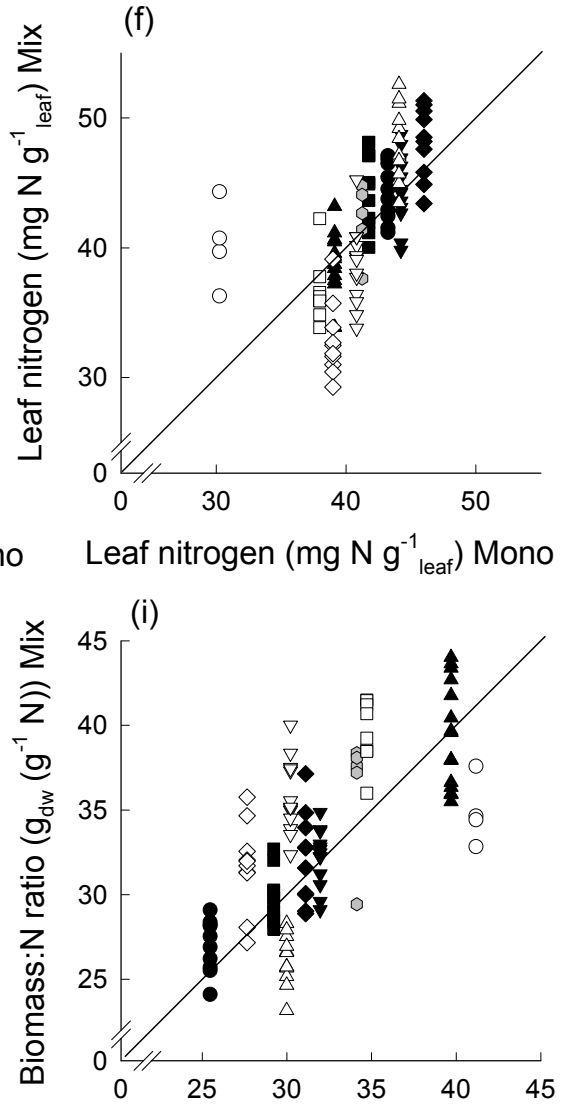

Biomass: $\mathrm{N}$ ratio $\left(\mathrm{g}_{\mathrm{dw}}\left(\mathrm{g}^{-1} \mathrm{~N}\right)\right)$ Mono 
Figure S3: Trait values per species averaged across all plots (mean \pm SE) in late summer (before second mowing: Aug) plotted against trait values in early summer (before first mowing: June). For species symbols see Fig. 3.

(a)

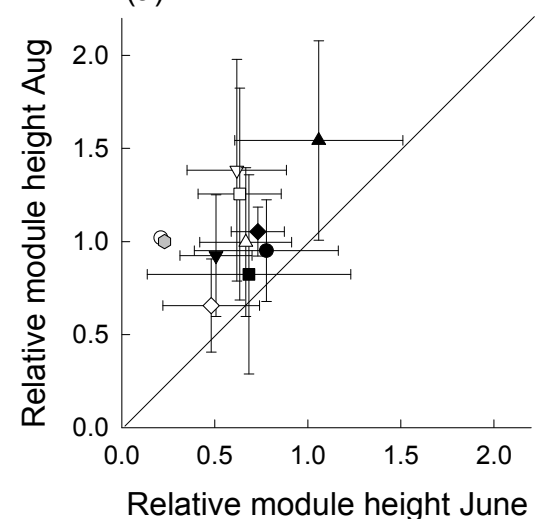

(d)

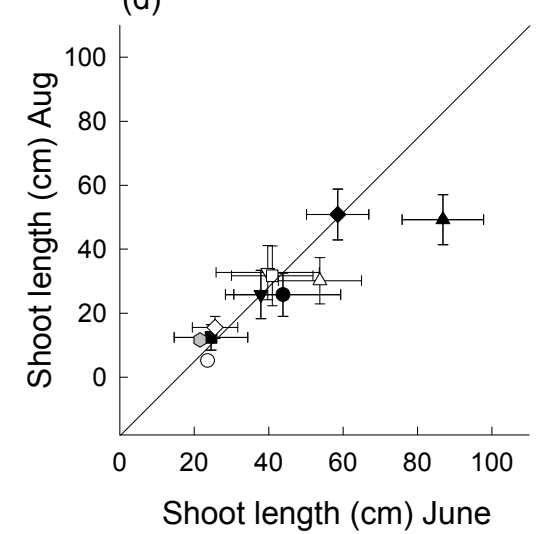

(g)

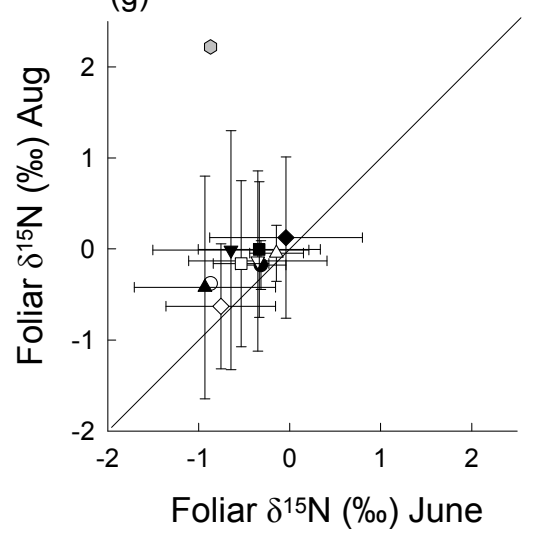

(b)

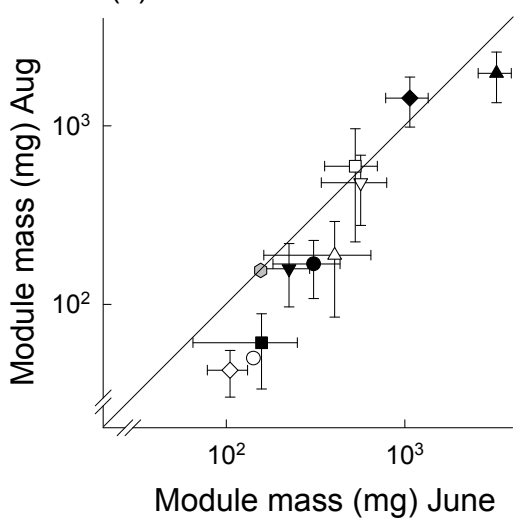

(e)

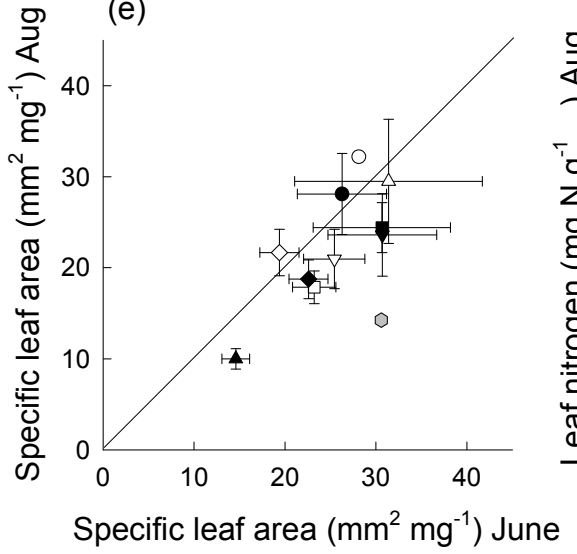

(h)

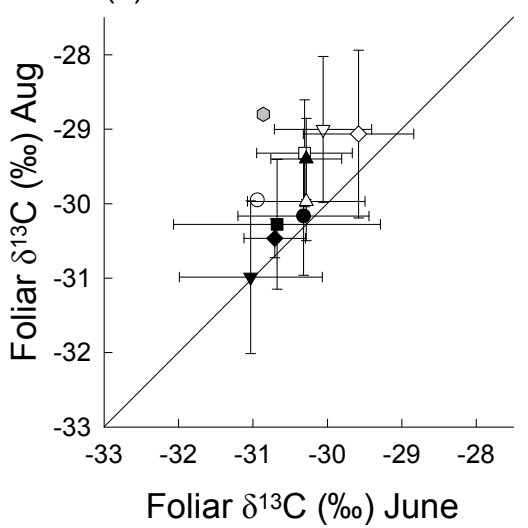

(c)

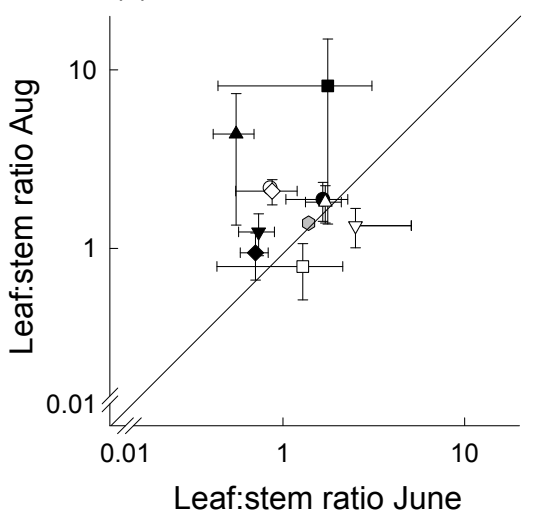

(f)

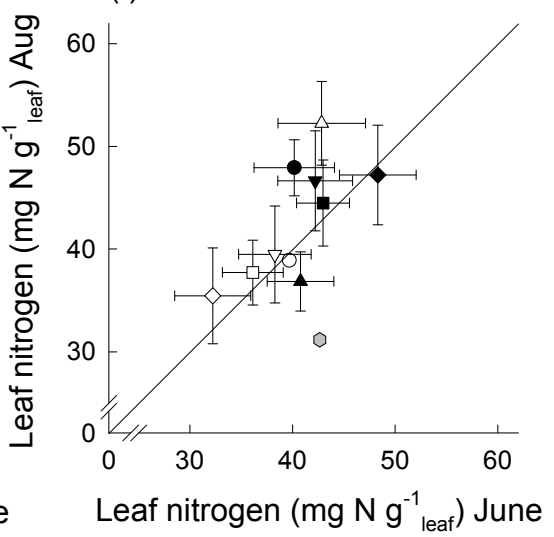

(i)

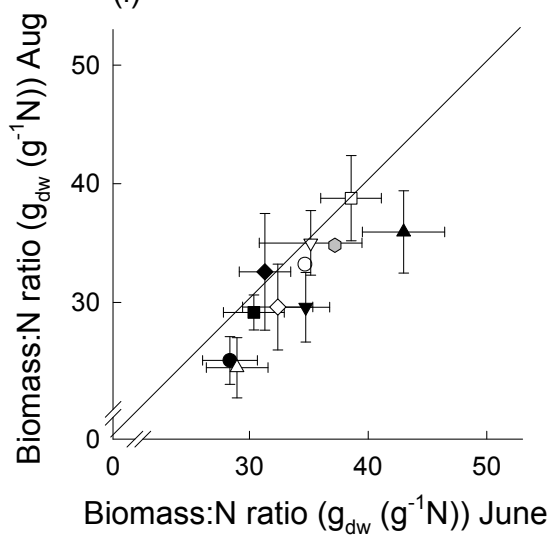

